\title{
The State of the Art of Electric and Hybrid Vehicles
}

\author{
C. C. CHAN, FELLOW, IEEE
}

Invited Paper

\begin{abstract}
In a world where environment protection and energy conservation are growing concerns, the development of electric vehicles $(E V)$ and hybrid electric vehicles (HEV) has taken on an accelerated pace. The dream of having commercially viable EVs and HEVs is becoming a reality. EVs and HEVs are gradually available in the market. This paper will provide an overview of the present status of electric and hybrid vehicles worldwide and their state of the art, with emphasis on the engineering philosophy and key technologies. The importance of the integration of technologies of automobile, electric motor drive, electronics, energy storage, and controls and also the importance of the integration of society strength from government, industry, research institutions, electric power utilities, and transportation authorities are addressed. The challenge of EV commercialization is discussed.
\end{abstract}

Keywords-Electric and hybrid vehicles, electric drives, electric propulsion.

\section{INTRODUCTION}

Electric vehicle (EV) is a road vehicle which involves with electric propulsion. With this broad definition in mind, EVs may include battery electric vehicles (BEVs), hybrid electric vehicles (HEVs), and fuel-cell electric vehicles (FCEVs). $\mathrm{EV}$ is a multidisciplinary subject which covers broad and complex aspects. However, it has core technologies, namely, chassis and body technology, propulsion technology, and energy source technology. It is a tough task to write a survey paper on this multidisciplinary subject. Although this paper is written based on BEV, it also addresses the major issues of emerging HEV and FCEV. The paper begins with reviewing the status of BEV and HEV, then focusing on the engineering philosophy of EV development. Subsequent to the illustration of the configurations of both BEV and HEV, it discusses

Manuscript received April 11, 2001; revised August 10, 2001. This paper was supported by the Hong Kong Research Grant Council under Grant HKU 7035/97E.

The author is with the Department of Electrical and Electronic Engineering, the University of Hong Kong, Hong Kong.

Publisher Item Identifier S 0018-9219(02)01129-5. in detail the major technologies, namely, the propulsion technology, energy source technology, and infrastructure technology. Finally, the commercialization aspects are discussed. The conclusion summarizes the state of the art and the challenges of BEV, HEV, and FCEV.

Today, BEV, HEV, and FCEV are in different stages of development, facing different challenges and requiring different strategies. In order to assist the reader's appreciation of the features and issues of these vehicles before reading the whole text, the major characteristics of these three types of vehicles are given in Table 1. It can be seen that the critical issue of BEV is the battery. Therefore, BEV is mainly suitable for small EV for short-range low-speed community transportation, which requires only smaller battery size. HEV can meet consumers' meet, but cost is the major issue. FCEV has long-term potential for future mainstream vehicles. However, the technology is still in the early development stage because its cost and refueling system are the major concerns.

\section{Why EleCtRIC VeHICLES?}

Let us begin with the investigation of the growth of population and vehicles, as shown in Fig. 1. In the next 50 years, the global population will increase from 6 billion to 10 billion and the number of vehicles will increase from 700 million to 2.5 billion. If all these vehicles are propelled by internal combustion engines (ICEs), where will the oil come from? Where should the emissions be disseminated? Would the sky be permanently grey? The gloomy answers to these questions compel people to strive for sustainable road transportation for the 21st century [1], [2].

In a world where environmental protection and energy conservation are growing concerns, the development of EV technology has taken on an accelerated pace to fulfill these needs. Concerning the environment, EVs can provide emission-free urban transportation. Even taking into account the emissions from the power plants needed to fuel the vehicles, the use of EVs can still significantly reduce global air pollution. From the energy aspect, EVs can offer a secure, 
Table 1

Characteristics of BEV, HEV, and FCEV

\begin{tabular}{|c|c|c|c|}
\hline Types of EVs & Battery EVs & Hybrid EVs & Fuel Cell EVs \\
\hline Propulsion & - $\quad$ Electric motor drives & $\begin{array}{ll}- & \text { Electric motor drives } \\
\text { - } & \text { Internal combustion engines }\end{array}$ & - $\quad$ Electric motor drives \\
\hline Energy system & $\begin{array}{ll} & \text { Battery } \\
\text { - } & \text { Ultracapacitor }\end{array}$ & $\begin{array}{ll} & \text { Battery } \\
- & \text { Ultracapacitor } \\
- & \text { ICE generating unit } \\
\end{array}$ & - $\quad$ Fuel cells \\
\hline $\begin{array}{l}\text { Energy source \& } \\
\text { infrastructure }\end{array}$ & $\begin{array}{l}\text { Electric grid charging } \\
\text { facilities }\end{array}$ & $\begin{array}{ll}- & \text { Gasoline stations } \\
\text { - Electric grid charging } & \text { facilities (optional) } \\
\end{array}$ & $\begin{array}{ll}\text { - } & \text { Hydrogen } \\
\text { - } & \text { Methanol or gasoline } \\
\text { Ethanol }\end{array}$ \\
\hline Characteristics & $\begin{array}{ll}- & \text { Zero emission } \\
- & \text { Independence on crude oils } \\
\text { - } & 100-200 \mathrm{~km} \text { short range } \\
\text { - } & \text { High initial cost } \\
\text { - } & \text { Commercially available }\end{array}$ & $\begin{array}{ll}\text { - } & \text { Very low emission } \\
\text { - } & \text { Long driving range } \\
\text { - } & \text { Dependence on crude oils } \\
\text { - } & \text { Complex } \\
\text { - } & \text { Commercially available }\end{array}$ & $\begin{array}{ll}\text { - } & \text { Zero emission or ultra low } \\
\text { emission } \\
\text { - } \quad \text { High energy efficiency } \\
\text { - } \quad \text { Independence on crude oils } \\
\text { - } \quad \text { High cost now } \\
\text { - Under development }\end{array}$ \\
\hline Major issues & $\begin{array}{l}\text { - } \begin{array}{l}\text { Battery and battery } \\
\text { management }\end{array} \\
\text { High performance } \\
\text { propulsion } \\
\text { - Charging facilities }\end{array}$ & $\begin{array}{ll} & \text { Managing multiple energy } \\
\text { - } & \text { Dources } \\
\text { - } & \text { Battery sizing and } \\
\text { management }\end{array}$ & $\begin{array}{ll}\text { - } & \text { Fuel cell cost } \\
\text { - } & \text { Fuel processor } \\
\text { - } & \text { Fueling system }\end{array}$ \\
\hline
\end{tabular}

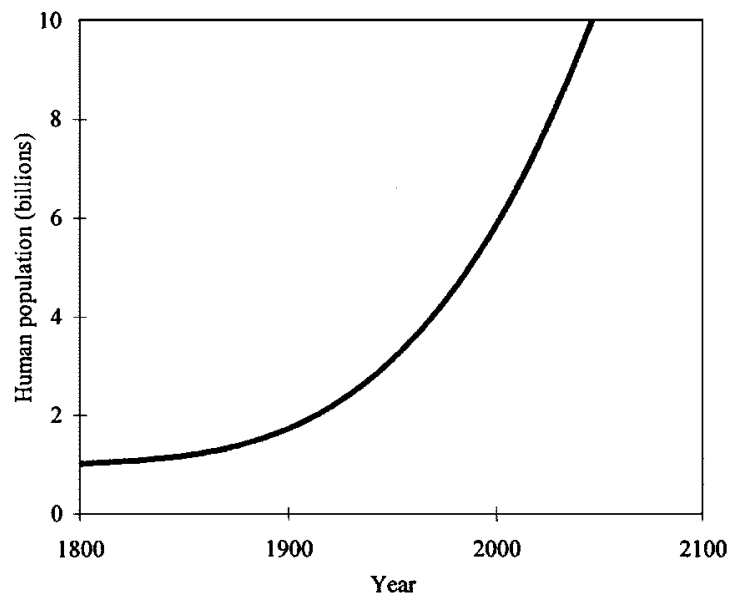

(a)

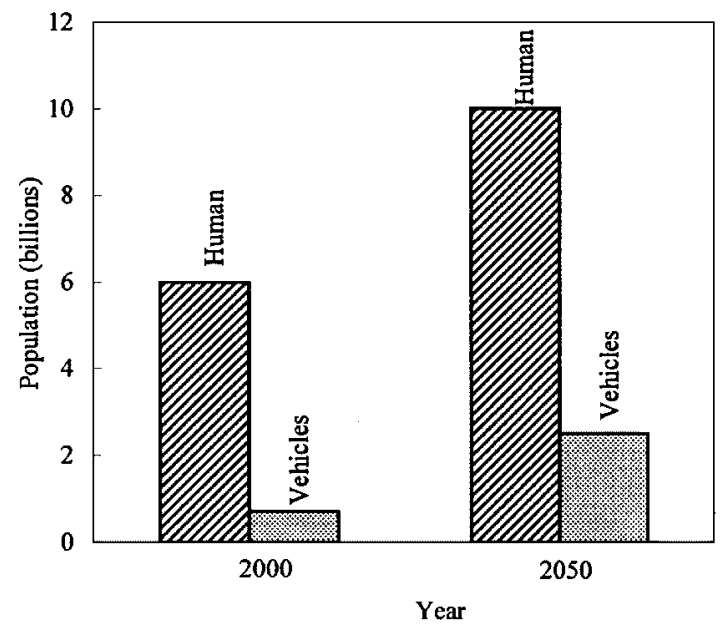

(b)

Fig. 1. Growth of population and vehicles.

comprehensive, and balanced energy option that is efficient and environmental friendliness, such as the utilization of various kinds of the renewable energies. Therefore, EVs will have the potential to have a great impact on energy, environment and transportation as well as hi-tech promotion, new industry creation, and economic development.

\section{PASt, Present, AND Future OF EVs}

\section{A. Past Years Development}

EV was invented in 1834. During the last decade of the 19th century, a number of companies produced EVs in America, Britain, and France. Fig. 2 shows the London Electric Cab Company's taxi. Due to the limitations associated with the batteries and the rapid advancement of internal combustion engine vehicles (ICEVs), EVs have almost vanished from the scene since 1930.

In the early 1970s, some countries, compelled by the energy crisis, started the rekindling of interests in EVs. In 1976, the USA launched the Electric and Hybrid Vehicle Research, Development, and Demonstration Act, Public Law 94-413. At that time, the main question to be answered was "Can EVs do the job in our modern society?" although EVs did work well in the late 1800s and early 1900s. The development of EVs over the years has answered the above question-yes. For example, an experimental EV in 1968 racing from the California Institute of Technology (Caltech) to the Massachusetts Institute of Technology (MIT) suffered from failures in virtually every critical component, whereas a commercially built EV in 1998 running from Los Angeles to Detroit exhibited a success with no component failures. Within the 1970s, EVs were still in research and development stage and most of them were conversion of ICEVs. Today, major automobile manufacturers are offering EVs for sale or lease. Most of them are the purpose-built EV, not conversion EV [1], [16]

\section{B. Present Major Issues}

At present, the major driving force for EVs is the environment issue, such as mandate by California rule, rather 


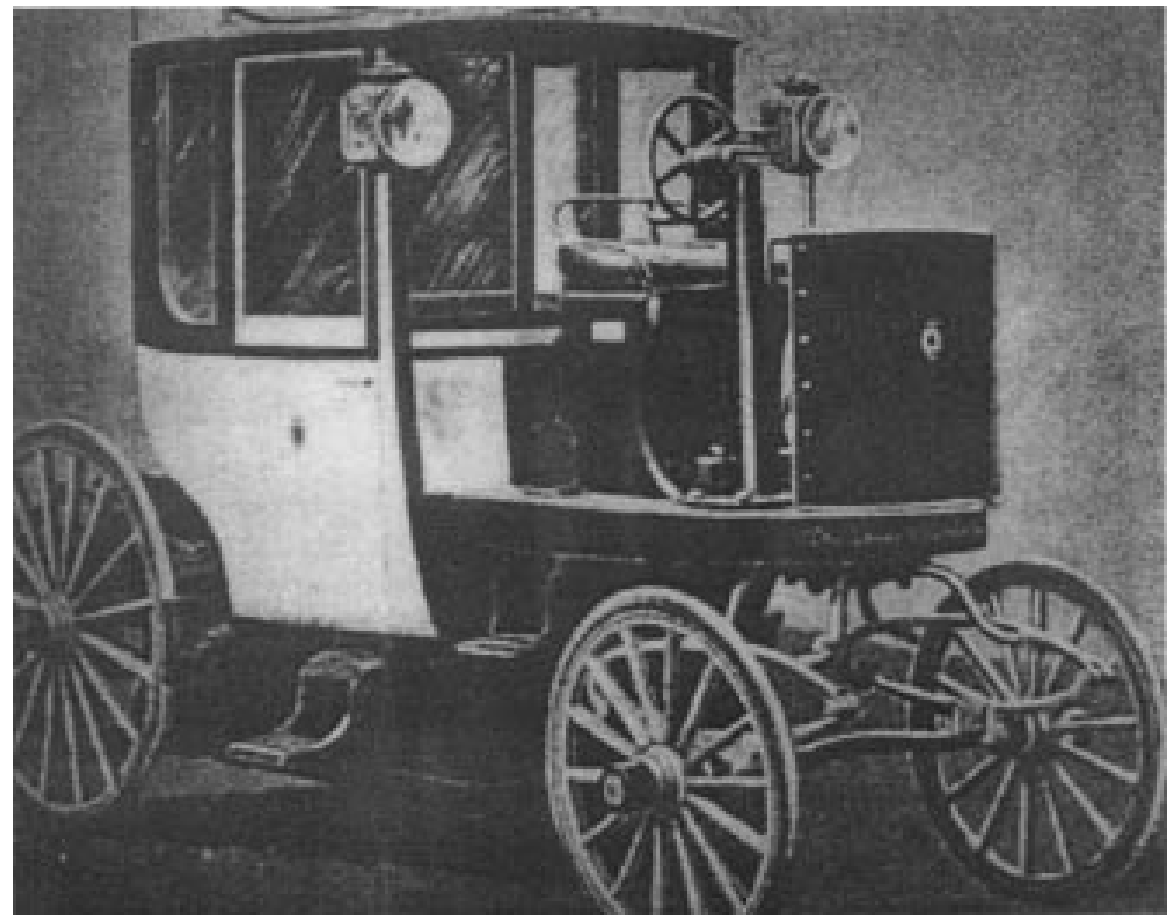

Fig. 2. London electric cab company's taxi (courtesy of Scientific American supplement; photo courtesy of History of the Electric Automobile by Ernest H. Wakefied).

than the previous energy issue. Thus, the main question to be answered becomes "Can EVs be made affordable?" The major factors that make EV affordable are the range and cost. To tackle the range, the development of advanced batteries such as nickel-metal hydride (Ni-MH), zinc/air (Zn/Air), and lithium-ion (Li-Ion) are in progress. However, since both specific energy and energy density of batteries are much lower than that of gasoline, the development of fuel cells (FCs) for EVs has taken on an accelerated pace in recent years. Meanwhile, the development of commercial HEVs is also going on rapidly. HEVs essentially improve the range and performance of EVs at higher complexity and cost because of the additional energy source, engine, and other accessories. To tackle the cost, efforts are being made to improve various EV subsystems, such as electric motors, power converters, electronic controllers, energy management units, battery chargers, batteries, and other EV auxiliaries, as well as EV system-level integration and optimization.

\section{Development Trends}

In order to see the development trends of various EV aspects, a survey has been made with respect to the number of papers published on various topics in leading EV related international conferences from 1984 to 2001. With regard to propulsion system, it was observed that the research papers on induction motor (IM) drives and permanent magnet (PM) motor drives are highly dominant, whereas those on direct current (DC) motor drives are dropping while those on switched reluctance (SR) motor drives are still in a crawling stage. With regard to the development trend of various energy sources, including lead-acid (LA) batteries , nickel-based (NB) batteries, lithium-based (LB) batteries, FCs, and capacitors/flywheels (CFs). The number of papers published in $\mathrm{LB}, \mathrm{FC}$, and $\mathrm{CF}$ are becoming more and more attractive, though LA and NB are still undergoing continual improvement. With regard to the configurations of EVs, it was observed that the conversion $\mathrm{EV}$ is becoming less attractive than the purpose-built EV, while the $\mathrm{HEV}$ is of growing interest for the coming $\mathrm{EV}$ markets. It was also observed that EVs are on the verge of commercialization, since more and more papers were published on the topics of demonstration as well as standardization and marketing of EVs.

In the next few decades, it is anticipated that both EVs and HEVs will be commercialized and they will have their market shares. EVs will be well accepted by some niche markets, namely, the users for community transportation, the places where electricity is cheap, and ease of access and the places with zero-emission mandate. On the other hand, HEVs will have a niche market for those users desiring long driving ranges. The ultimate penetration of EVs and HEVs will mainly depend on their respective costs. The commercialization of FCEVs will be accelerated in later decades, since they have the greatest potential to deliver the same range and performance as our ICEVs, but now it is still in the development stage.

In summary, electric propulsion and energy sources will still be the key technologies to be addressed and EVs and HEVs will still be coexistent, while energy, environment, and economy will still be the key issues for EV commercialization. Fig. 3 illustrates the development trends of EVs and HEVs. It should be noted that some core technologies can 


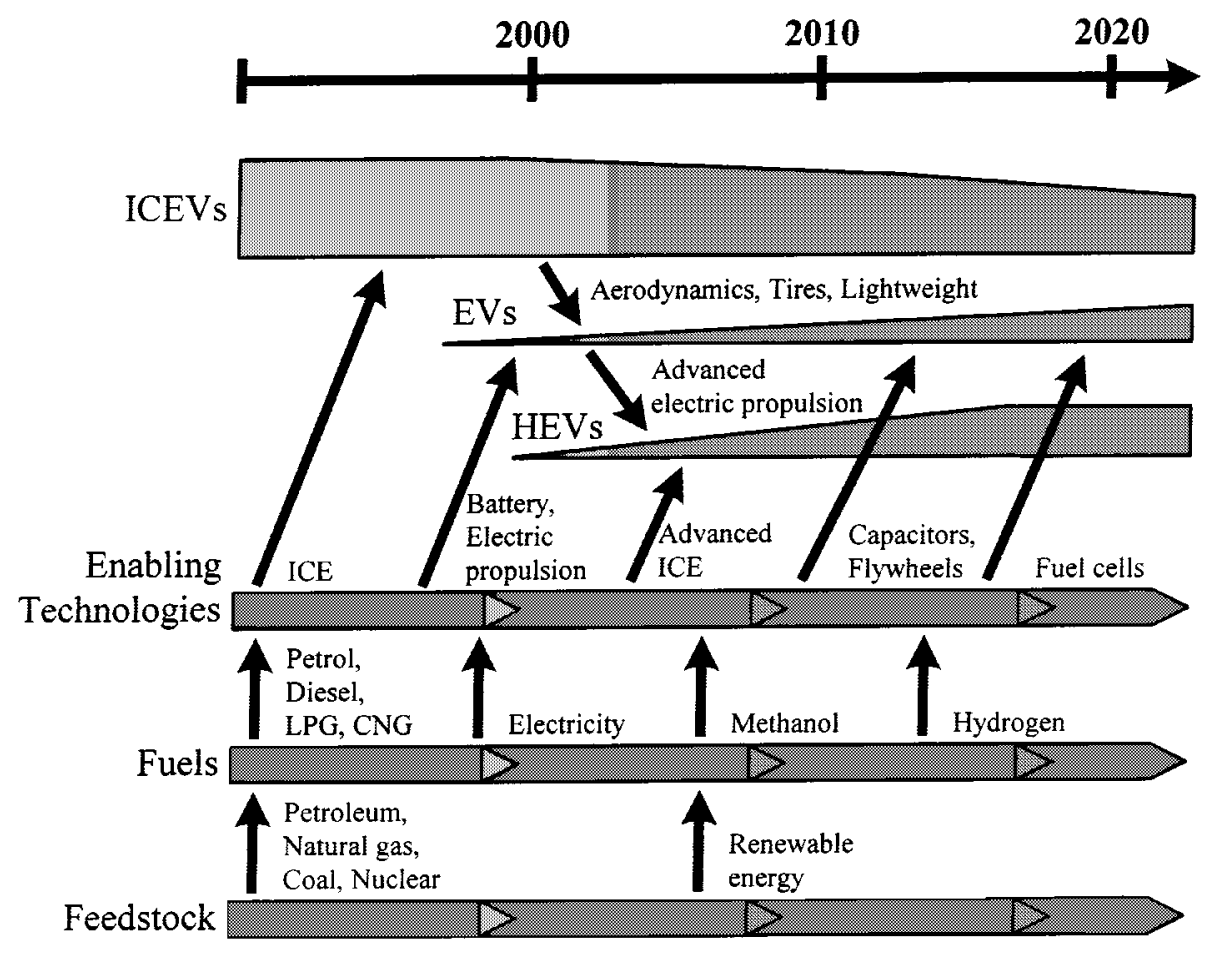

Fig. 3. Development trends of EVs and HEVs (courtesy of EVAA).

be shared among ICEVs, EVs, and HEVs. Our ultimate goal is the use of clean, efficient, and intelligent energy to achieve sustainable transportation system for the 21 st century.

\section{Present Status}

After many years of development, EV technologies are becoming mature. Many advanced technologies are employed to extend the driving range and reduce the cost. For example, the use of advanced IM drives and PM brushless motor drives to improve the electric propulsion system, the employment of advanced valve-regulated lead-acid (VRLA) battery, Ni-MH battery, Li-Ion battery, FCs, and ultracapacitors to improve the EV energy source, application of light body technology with light, but rigid material, low-drag coefficient body to reduce the aerodynamic resistance and low rolling resistance tires to reducing running resistance at low and medium driving speed, as well as the adoption of advanced charging, power steering, or variable temperature seats to enhance the EV auxiliaries. In the following paragraphs, some of the recently developed EV, HEV, and FCEV are illustrated with the intention to show the achievable technology, despite particular vehicle model. For example, EV1 has been discontinued and some models are for demonstration purpose only, i.e., NECAR5 and Ford P2000. These typical vehicles have been carefully chosen to represent the state of the art. GM EV1 and Nissan Altra EV represent advanced BEV using different types of motor and battery. Ford 2000P and NECAR5 represent the development stage of FCEV, Toyota Prius and Honda Insight represent the commercialization of HEV, Luciole and HKU 200 represent showcase BEV, and Reva represents commercially produced low-cost BEV.
Showcasing the most advanced propulsion system, the 1997 two-seater GM EV1 is shown in Fig. 4. It had a front-wheel drive that adopted a $102-\mathrm{kW}$ three-phase IM and a single-speed transaxle with dual-reduction of 10.946:1. It contained 26-module 312-V VRLA batteries that were inductively charged by a $6.6-\mathrm{kW}$ offboard charger or a 1.2-kW onboard charger. This EV1 could offer an axle torque of $1640 \mathrm{Nm}$ from zero to $7000 \mathrm{rpm}$ and a propulsion power of $102 \mathrm{~kW}$ from 7000 to $14000 \mathrm{rpm}$, leading to achieve a top speed of $128 \mathrm{~km} / \mathrm{h}$ (electronically limited) and an acceleration from zero to $96 \mathrm{~km} / \mathrm{h}$ in less than $9 \mathrm{~s}$. For city driving, it could provide a range of $112 \mathrm{~km}$ per charge, whereas on highway operation, it offered $144 \mathrm{~km}$ per charge. In 1999, the EV1 adopted nickel-metal hybrid batteries as an optional equipment, hence, reaching $220 \mathrm{~km}$ per charge.

Fig. 5 shows the 1997 four-seater Altra EV, which was the flagship of Nissan. It used a 62-kW PM brushless motor, which weighed only $39 \mathrm{~kg}$, the highest power-to-weight ratio $(1.6 \mathrm{~kW} / \mathrm{kg})$ for any EV motor available. Making use of maximum efficiency control, the total efficiency of the propulsion system was more than $89 \%$. Power came from the cobaltbased Li-Ion batteries, which had a specific energy of 90 $\mathrm{Wh} / \mathrm{kg}$, a specific power of $300 \mathrm{~W} / \mathrm{kg}$, and a long cycle life of about 1200 recharges. This battery pack could be charged up by an onboard inductive charging system within five hours. It could achieve a top speed of $120 \mathrm{~km} / \mathrm{h}$ and a range of $192 \mathrm{~km}$ for city driving. In 1999, the Altra adopted the manganese-based Li-Ion batteries to further increase both specific energy and specific power to $91 \mathrm{Wh} / \mathrm{kg}$ and $350 \mathrm{~W} / \mathrm{kg}$, respectively.

The Ford P2000 symbolized the dedication of Ford in the development of FCEVs. Fig. 6 shows this four-door sedan, 


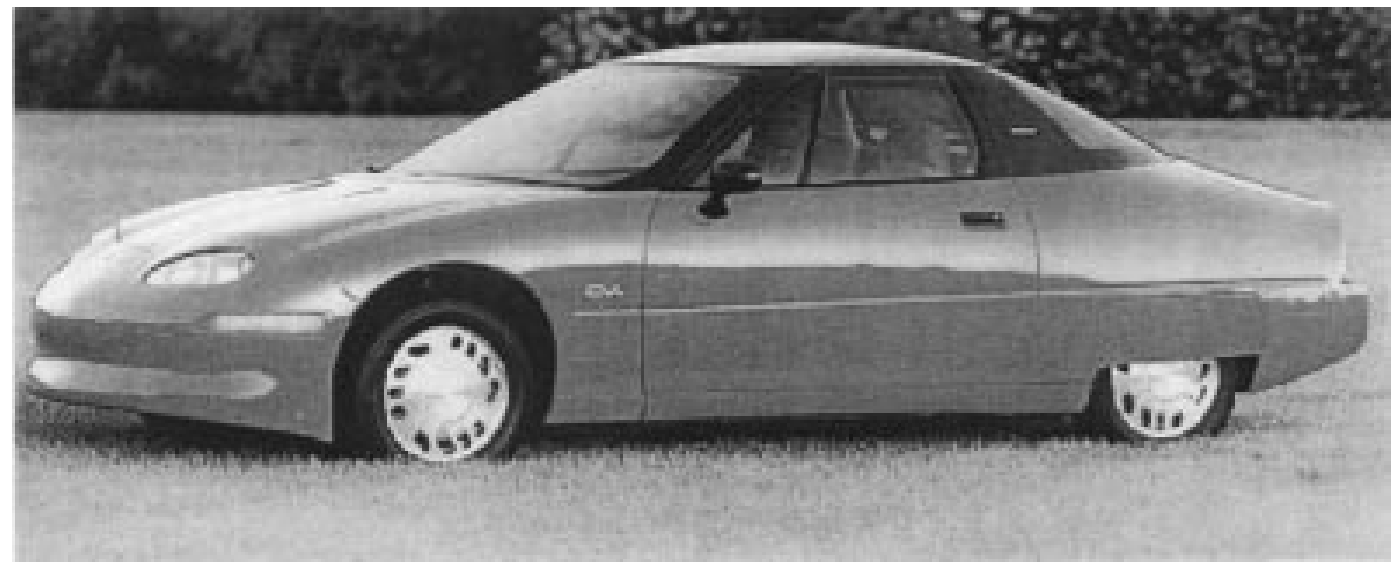

Fig. 4. GM EV1 (photo courtesy of General Motors).

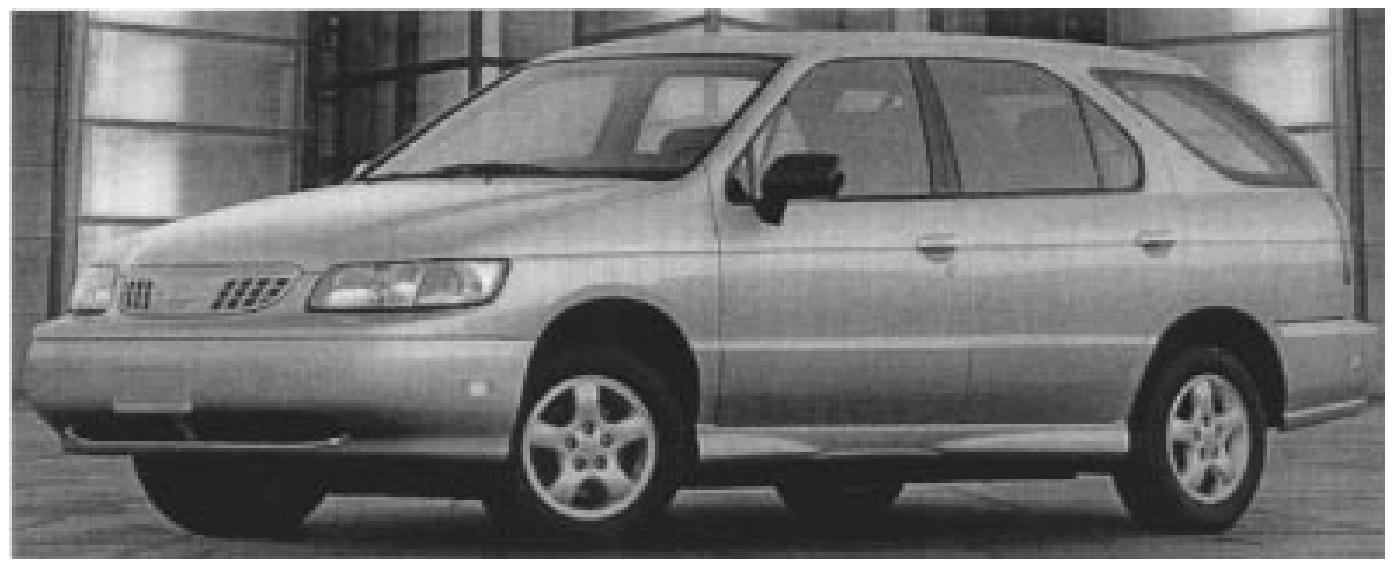

Fig. 5. Nissan Altra EV (photo courtesy of Nissan).

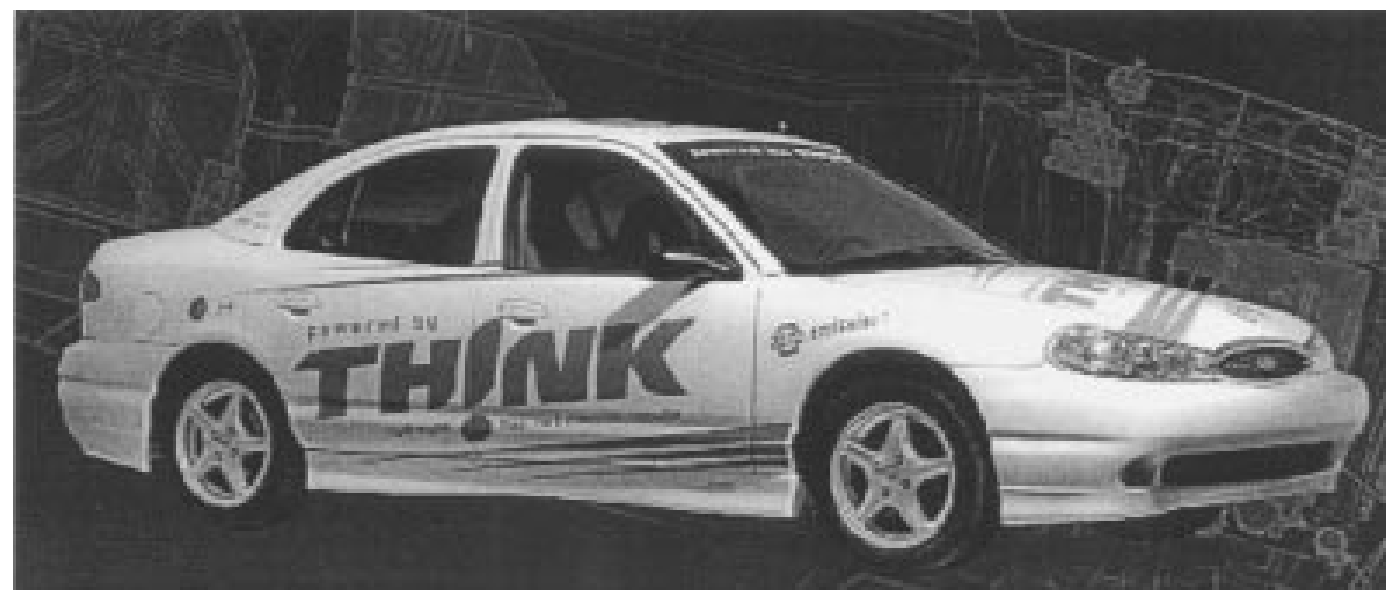

Fig. 6. Ford P2000 (photo courtesy of Ford Motor Company).

which was launched in the year 2000. It was powered by the Ford's Th!nk FC system, namely, the proton exchange membrane (PEM) FCs, which was fuelled by compressed hydrogen gas $(\mathrm{CHG})$ stored at $25 \mathrm{MPa}$ and oxygen gas simply from the air. It adopted a three-phase IM, offering a peak power of $67 \mathrm{~kW}$, a peak torque of $190 \mathrm{Nm}$, and a peak efficiency of $91 \%$. With the curb weight of $1514 \mathrm{~kg}$, the P2000 could achieve a top speed of $128 \mathrm{~km} / \mathrm{h}$ and a driving range of $160 \mathrm{~km}$ per charge.
Daimler-Benz, now DaimlerChrysler, presented its first methanol-fuelled FCEV in 1997-the NECAR 3. It used PEM FCs to generate a power of $50 \mathrm{~kW}$ for propulsion. The hydrogen fuel was directly extracted from methanol via a mini reformer, thus bypassing the problem of having compressed gas canisters onboard the vehicle. The FCs were stored beneath the floor, while the reformer, methanol tank, and control systems were located in the boot. Based on this first generation methanol-fuelled FC propulsion system, 


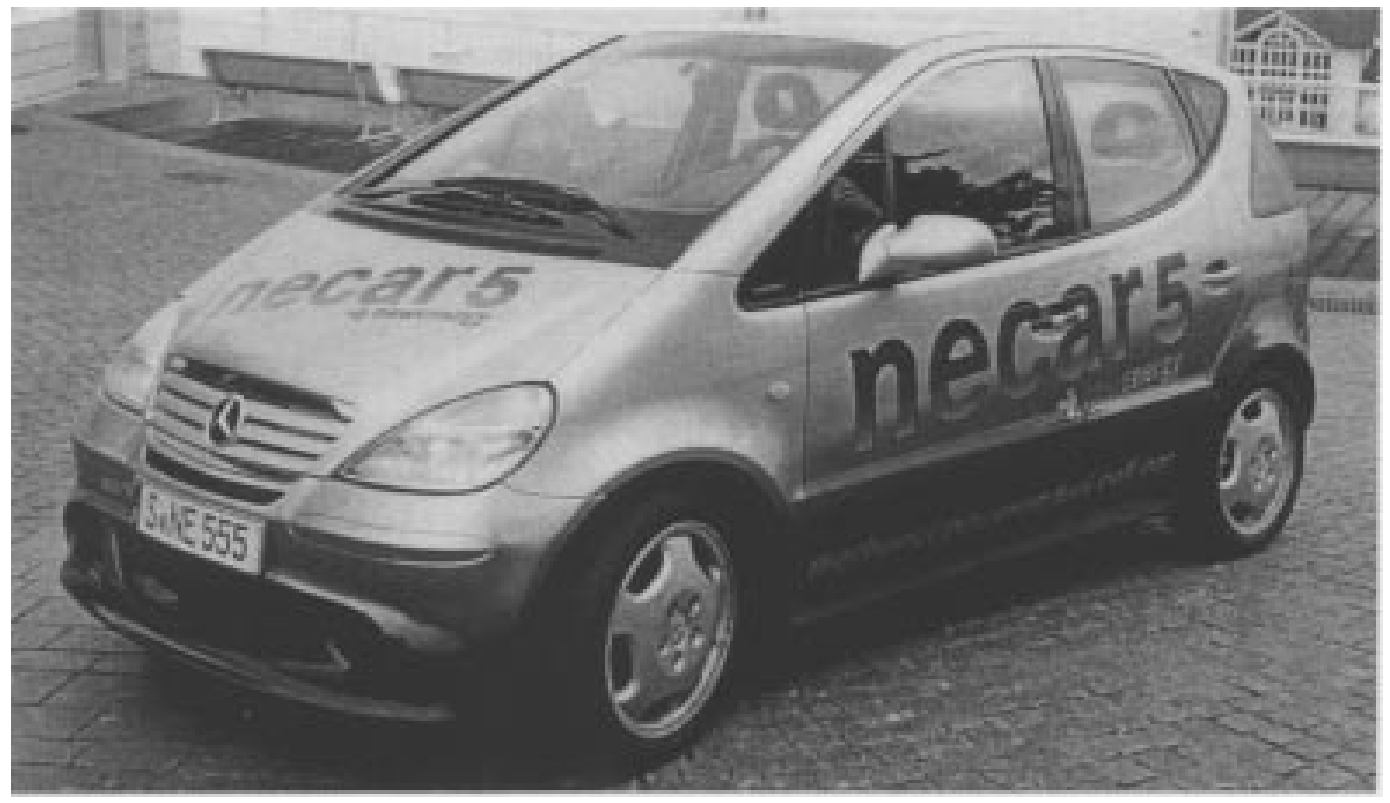

Fig. 7. DaimlerChrysler NECAR 5 (photo courtesy of DaimlerChrysler).

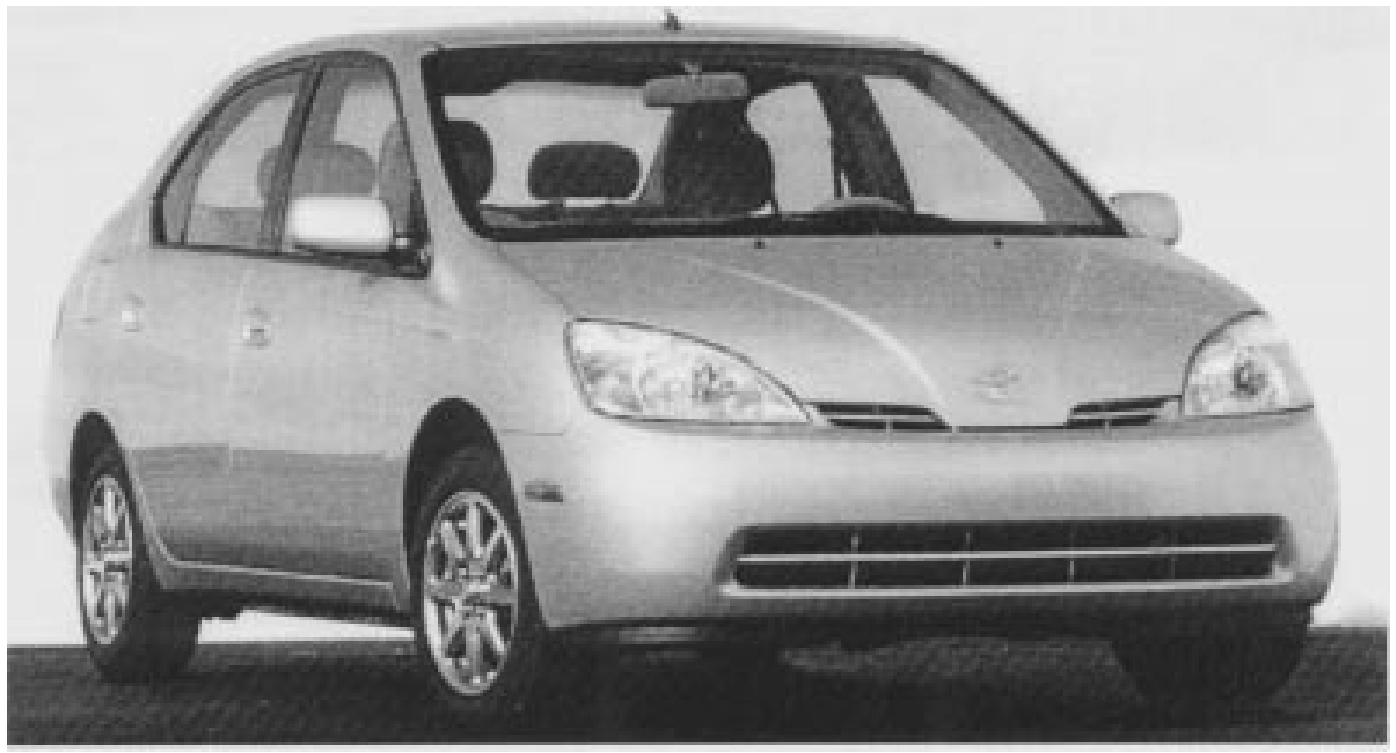

Fig. 8. Toyota Prius (photo courtesy of Toyota).

the NECAR 3 could travel over $400 \mathrm{~km}$ on $38 \mathrm{~L}$ of liquid methanol. As shown in Fig. 7, the NECAR 5 launched in 2000 was the technological successor of the NECAR 3, while reducing the size of the drive system by half and the weight of the vehicle by $300 \mathrm{~kg}$. It also boosted up the power to $75 \mathrm{~kW}$ to reach speeds over $150 \mathrm{~km} / \mathrm{h}$.

The world's first mass-production HEV was the Toyota Prius, as shown in Fig. 8. Its motive power was sourced from both a four-cylinder ICE (52 kW at $4500 \mathrm{rpm})$ and a PM brushless motor ( $33 \mathrm{~kW}$ at $1040-5600 \mathrm{rpm})$. Since it was an ICE-heavy HEV, a power split device, namely, the planetary gear, sent part of the ICE power to the wheels and part to a generator. The generated electrical energy could supply the electric motor to increase the motive power or could be stored in the 38-module nickel-metal hybrid batteries. The Prius could offer a top speed of $160 \mathrm{~km} / \mathrm{h}$, an acceleration from zero to $96 \mathrm{~km} / \mathrm{h}$ in $12.7 \mathrm{~s}$, and a fuel economy of 20 $\mathrm{km} / \mathrm{l}$ for combined city and highway operation. Both of its fuel economy and exhaust emissions were much better than that of any conventional ICEVs.

The Honda Insight, shown in Fig. 9, went on sale in December 2000. It employed an ICE-heavy hybrid system, combining a three-cylinder ICE (50 kW at $5700 \mathrm{rpm}$ ) and a $\mathrm{PM}$ synchronous motor $(10 \mathrm{~kW}$ at $3000 \mathrm{rpm})$. The electric motor was powered by a $144-\mathrm{V}$ Ni-MH battery pack, which was recharged by regenerative braking during normal cruising and downhill driving. The Insight was claimed to be the most fuel-efficient HEV with the fuel economy of 26-30 $\mathrm{km} / \mathrm{l}$. Also, it satisfied the stringent ultra low-emission vehicle (ULEV) standard in California.

To simultaneously address the problems of air pollution, wasteful energy consumption, and traffic safety, the Na- 


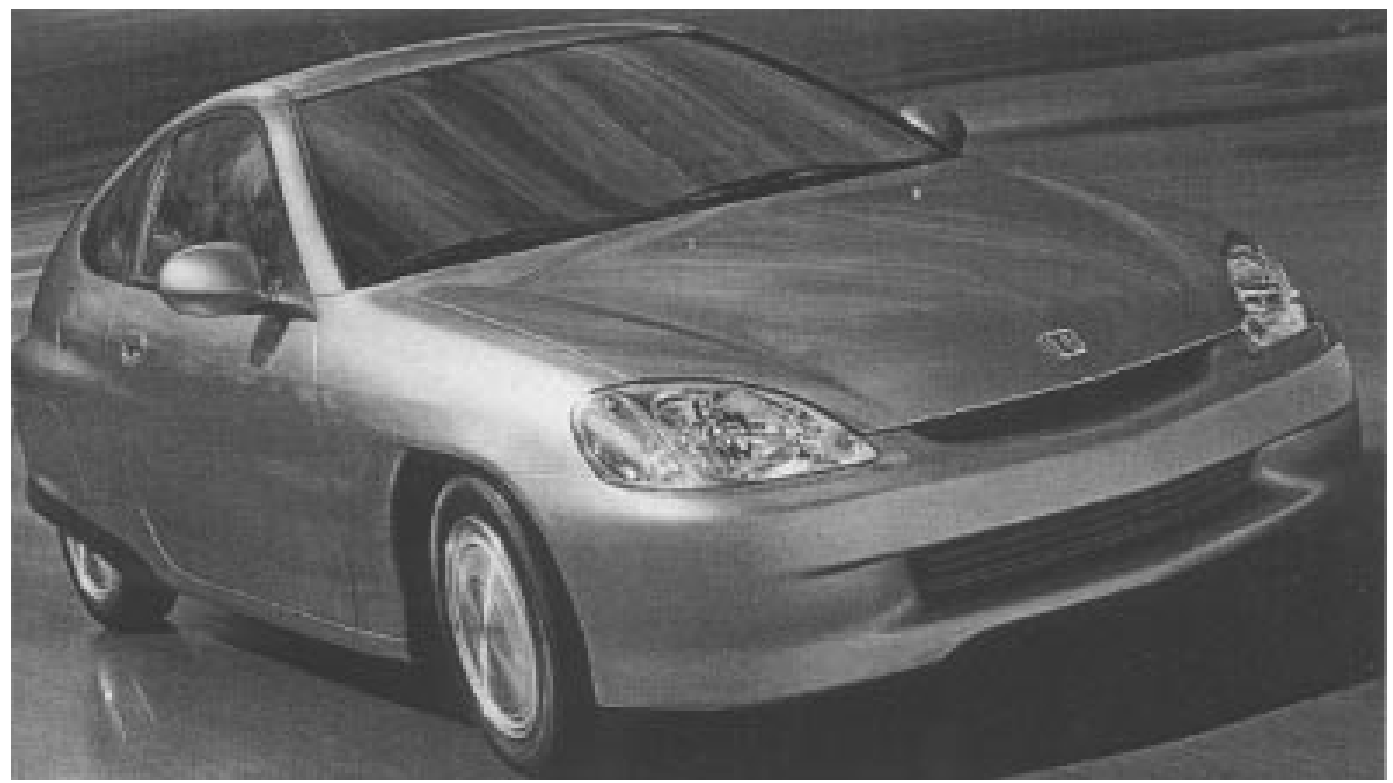

Fig. 9. Honda Insight (photo courtesy of Honda).

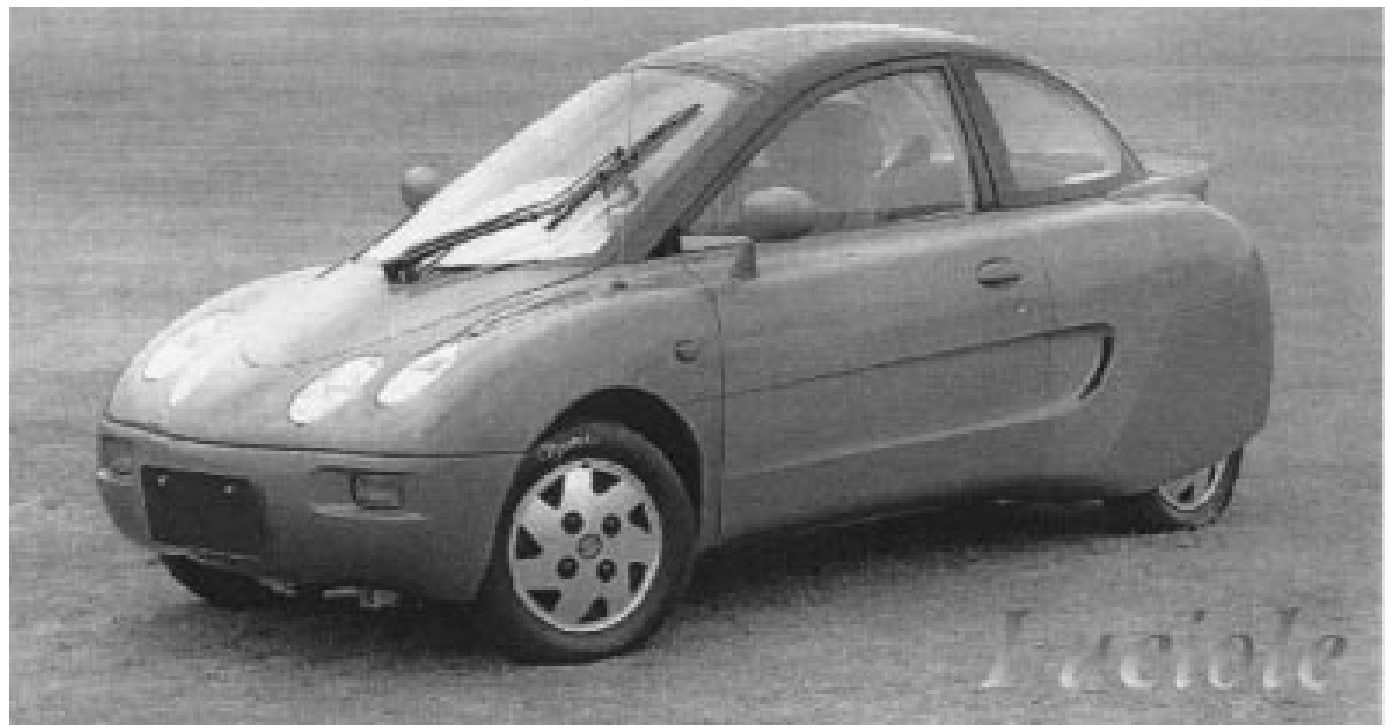

Fig. 10. NIES Luciole (photo courtesy of NIES, Japan).

tional Institute for Environmental Studies (NIES) in Japan presented a high-performance lightweight EV, namely, the Luciole (formerly called Eco-Vehicle) in 1996 for convenient city commuting. As shown in Fig. 10, it adopted a tandem two-seater layout so that the seats could be kept comfortable and the safety in side crushes could be improved by thickening the doors. It was rear-wheel drive, which was powered by two inwheel PM brushless motors with the total output of $72 \mathrm{~kW}$ and $154 \mathrm{Nm}$. The battery pack contained 224-V VRLA batteries, mounted inside the square holes of the purpose-built chassis. The battery pack could be charged up by normal charging within five hours, by fast charging within fifteen minutes or even partially charged by solar charging. The Luciole could achieve a top speed of $130 \mathrm{~km} / \mathrm{h}$, a range on the Japan 10.15 Mode driving cycle of $130 \mathrm{~km}$, and an acceleration from zero to $40 \mathrm{~km} / \mathrm{h}$ in $3.9 \mathrm{~s}$.
Fig. 11 shows an EV, the U2001, which was developed by the University of Hong Kong (HKU) in 1993. It was a four-seater $\mathrm{EV}$, which adopted a $45-\mathrm{kW}$ PM hybrid motor and a 264-V nickel-cadmium (Ni-Cd) battery pack. This specially designed EV motor could offer high efficiencies over a wide operating range. It also incorporated a number of advanced EV technologies, such as the adoption of thermoelectric variable temperature seats to minimize the energy used for air-conditioning, the use of an audio navigation system to facilitate safe and user-friendly driving, and the use of an intelligent energy management system (EMS) to optimize the energy flow within the vehicle. The U2001 could offer a top speed of $110 \mathrm{~km} / \mathrm{h}$, an acceleration from zero to $48 \mathrm{~km} / \mathrm{h}$ in $6.3 \mathrm{~s}$, and a range of $176 \mathrm{~km}$ at $88-\mathrm{km} / \mathrm{h}$ operation.

Apart from the USA, Europe, and Japan, India also plays an active role to commercialize EVs. Fig. 12 shows a 


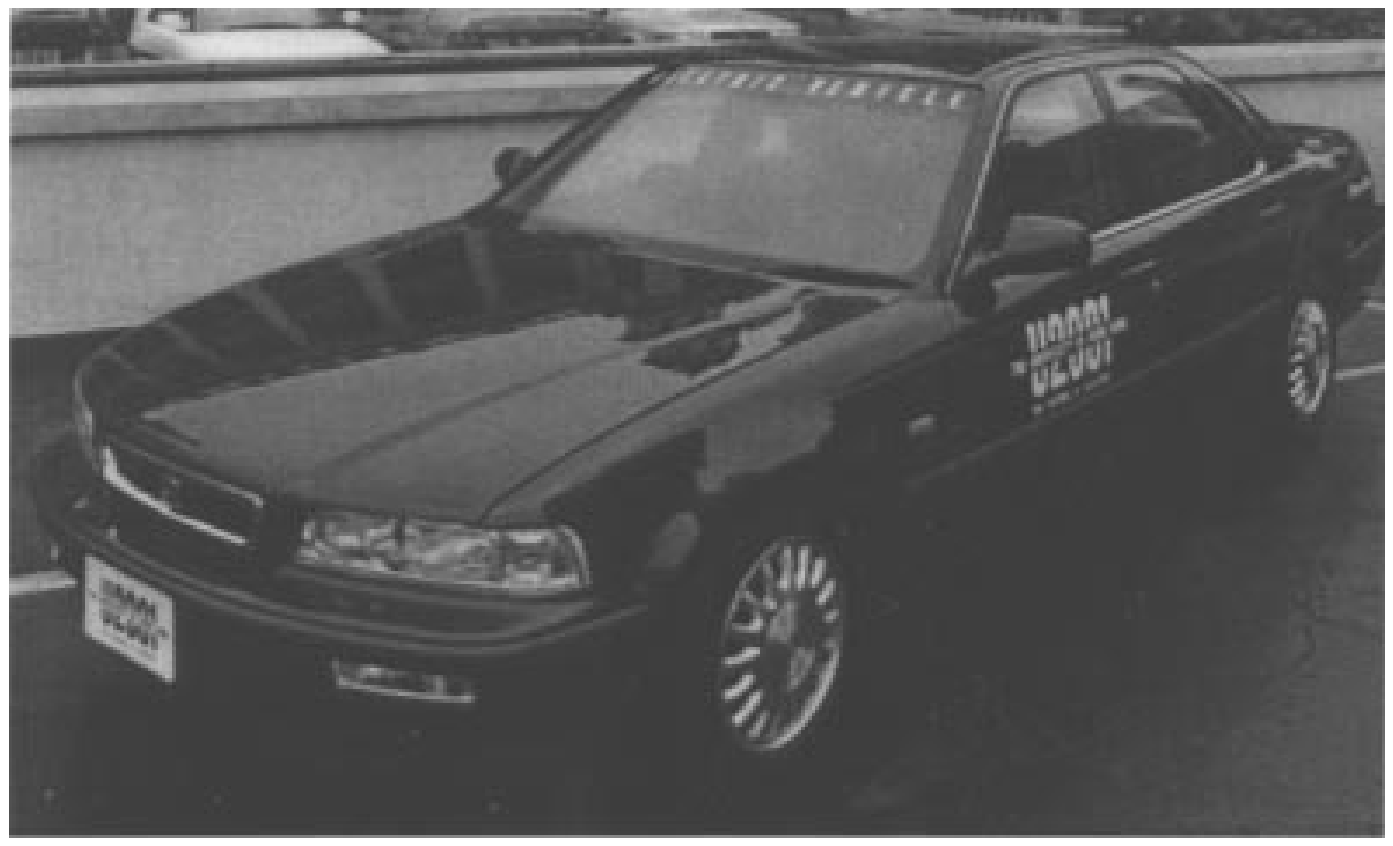

Fig. 11. HKU U2001.

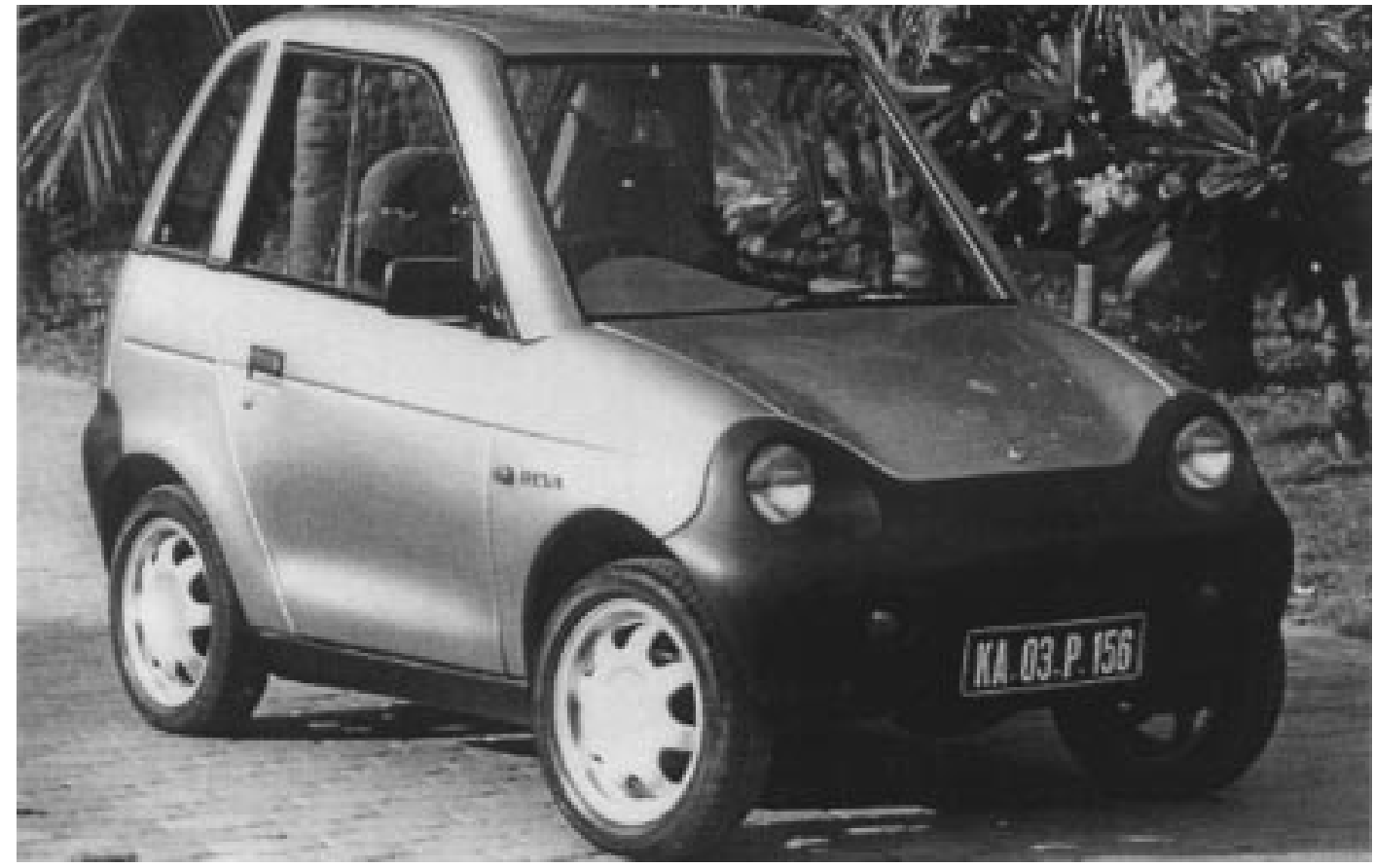

Fig. 12. Reva EV (photo courtesy of Reva Electric Car Company).

two-door hatchback EV, the Reva EV, which was launched in the year 2001 and would be India's first mass-produced EV. It adopted a separately excited DC motor $(70 \mathrm{Nm}, 13$ $\mathrm{kW}$ peak) and a $48-\mathrm{V}$ tubular LA battery pack. Its onboard charger $(220 \mathrm{~V}, 2.2 \mathrm{~kW})$ could provide $80 \%$ charge within 3 $\mathrm{h}$ and $100 \%$ within $6 \mathrm{~h}$. With the curb weight of $650 \mathrm{~kg}$, the Reva EV could achieve a top speed of $65 \mathrm{~km} / \mathrm{h}$ and a range of $80 \mathrm{~km}$ per charge. The most attractive feature was its incredibly low initial and running costs - the exfactory cost is about 5000 U.S. dollars and the running cost is less than one U.S. cent per kilometer. The major means of reducing the cost of this EV includes the system optimization and integration, low-cost local components, low-cost tooling, and simple automation.

It can be seen from Table 2 that the sale and lease of EVs in USA from 1996 to 2000 were not successful; the major reason was that their cost was too expensive and their driving range did not fully satisfy the users' need (Table 3 ). 
Table 2

EVs Sold/Leased in the USA 1996-2000

\begin{tabular}{ccccccccc}
\hline & $\begin{array}{c}\text { Chrysler } \\
\text { EPIC }\end{array}$ & $\begin{array}{c}\text { Ford Ranger } \\
\text { EV }\end{array}$ & GM EV1 & $\begin{array}{c}\text { GM S-10 } \\
\text { Electric }\end{array}$ & $\begin{array}{c}\text { Honda } \\
\text { EV Plus }\end{array}$ & $\begin{array}{c}\text { Nissan } \\
\text { Altra EV }\end{array}$ & $\begin{array}{c}\text { Toyota } \\
\text { RAV4-EV }\end{array}$ & $\begin{array}{c}\text { Total } \\
\text { (year) }\end{array}$ \\
\hline 1996 & N/A & N/A & 39 & N/A & N/A & N/A & N/A & 39 \\
1997 & 17 & 27 & 264 & 278 & 105 & N/A & 69 & 760 \\
1998 & 0 & 310 & 258 & 99 & 133 & 30 & 359 & 1189 \\
1999 & 129 & 533 & 138 & 123 & 62 & 30 & 255 & 1270 \\
2000 & 60 & 389 & 154 & 0 & 0 & 50 & 106 & 759 \\
Total & 206 & 1259 & 853 & 500 & 300 & 110 & 789 & 4017 \\
(per OEM) & & & & & & & & \\
\hline
\end{tabular}

Table 3

Key Data of Modern EVs

\begin{tabular}{|c|c|c|c|c|c|c|c|}
\hline \multirow[t]{2}{*}{ EVs } & \multirow[t]{2}{*}{ Batteries } & \multirow{2}{*}{$\begin{array}{c}\text { Driving } \\
\text { Range }(\mathrm{km})\end{array}$} & \multicolumn{2}{|c|}{ Weight (kg) } & \multirow{2}{*}{$\begin{array}{c}\text { Battery } \\
\text { Weights }(\mathrm{kg})\end{array}$} & \multicolumn{2}{|c|}{ Price (US\$) } \\
\hline & & & Curb & Passenger & & Sale & Rent \\
\hline \multirow[t]{2}{*}{ GM EV-1 } & $\mathrm{PbA}$ & $88-152$ & 1348 & 2 & 553 & 33,959 & 424 \\
\hline & NiMH & $120-208$ & 1205 & 2 & 410 & 43,995 & 499 \\
\hline \multirow{2}{*}{ GM S-10 } & $\mathrm{PbA}$ & $64-88$ & 1977 & $2 / 364 \mathrm{~kg}$ & 612 & 32,995 & N/A \\
\hline & NiMH & 104-128 & 1909 & $2 / 432 \mathrm{~kg}$ & N/A & 42,995 & N/A \\
\hline \multirow{2}{*}{$\begin{array}{c}\text { Ford Ranger } \\
\text { EV }\end{array}$} & $\mathrm{PbA}$ & 80 & 2243 & $2 / 395 \mathrm{~kg}$ & N/A & 32,795 & 349 \\
\hline & $\mathrm{NiMH}$ & $104-136$ & 1907 & $2 / 568 \mathrm{~kg}$ & $\mathrm{~N} / \mathrm{A}$ & 42,795 & 450 \\
\hline $\begin{array}{l}\text { Toyota } \\
\text { RAV4 }\end{array}$ & NiMH & 202 & 1564 & $5 / 376 \mathrm{~kg}$ & 450 & 45,000 & N/A \\
\hline $\begin{array}{c}\text { Honda } \\
\text { EV Plus }\end{array}$ & NiMH & $200-220$ & 1615 & 4 & 450 & 44,999 & 454 \\
\hline Nissan Altra & Li-Ion & 192 & 1704 & $4 / 372 \mathrm{~kg}$ & 350 & 50,999 & 599 \\
\hline $\begin{array}{c}\text { Chrysler } \\
\text { EPIC }\end{array}$ & NiMH & $128-144$ & -- & $5 / 363 \mathrm{~kg}$ & N/A & $\mathrm{N} / \mathrm{A}$ & 450 \\
\hline
\end{tabular}

\section{ENGINEERING PHILOSOPHY OF EV DEVELOPMENT}

\section{A. EV Concept}

Although the EV was around before the turn of the 20th century, the modern EV is a completely new machine that is totally different from the classical EV. It is not only a transportation vehicle, but also a new type of electric equipment. The modern EV concept is summarized as follows.

1) The EV is a road vehicle based on modern electric propulsion that consists of the electric motor, power converter, and energy source and it has its own distinct characteristics.

2) The EV is not just a car, but a new system for our society, realizing clean and efficient road transportation.

3) EV users' expectations must be studied and, hence, appropriate education must be conducted.

The system architecture of EVs has its own distinct features that may differ from that of ICEVs, similar to the fact that the system architecture of quartz-based electronic watches is very different from that of spring-based mechanical watches. In short, their appearances are very similar, whereas their principles are very different. The unique features of EVs must be fully appreciated.

\section{B. EV Engineering Philosophy}

The EV engineering philosophy essentially is the integration of automobile engineering and electrical engineering. Thus, system integration and optimization are prime considerations to achieve good EV performance at affordable cost. Since the characteristics of electric propulsion are fundamentally different from those of engine propulsion, a novel design approach is essential for EV engineering. Moreover, advanced energy sources and intelligent energy management are key factors to enable EVs competing with ICEVs. Of course, the overall cost effectiveness is the fundamental factor for the marketability of EVs.

The design approach of modern EVs should include state-of-the-art technologies from automobile engineering, electrical and electronic engineering, and chemical engineering, adopt unique designs particularly suitable for EVs, and develop special manufacturing techniques particularly suitable for EVs. Every effort should be made to optimize the energy utilization of EVs. The following points are those typical considerations for EV design.

1) Identify the niche market and environment.

2) Determine the technical specifications including the driving cycle.

3) Determine the infrastructure required including the recycling of batteries.

4) Determine the overall system configuration-BEV, $\mathrm{HEV}$, or FCEV configurations.

5) Determine the chassis and body.

6) Determine the energy source-generation or storage, single or hybrid.

7) Determine the propulsion system-motor, converter, and transmission types, single or multiple motors, gearless or geared, mounting methods, and ICE systems in case of an HEV.

8) Determine the specifications of electric propulsion (power, torque, speed) and energy source (capacity, 


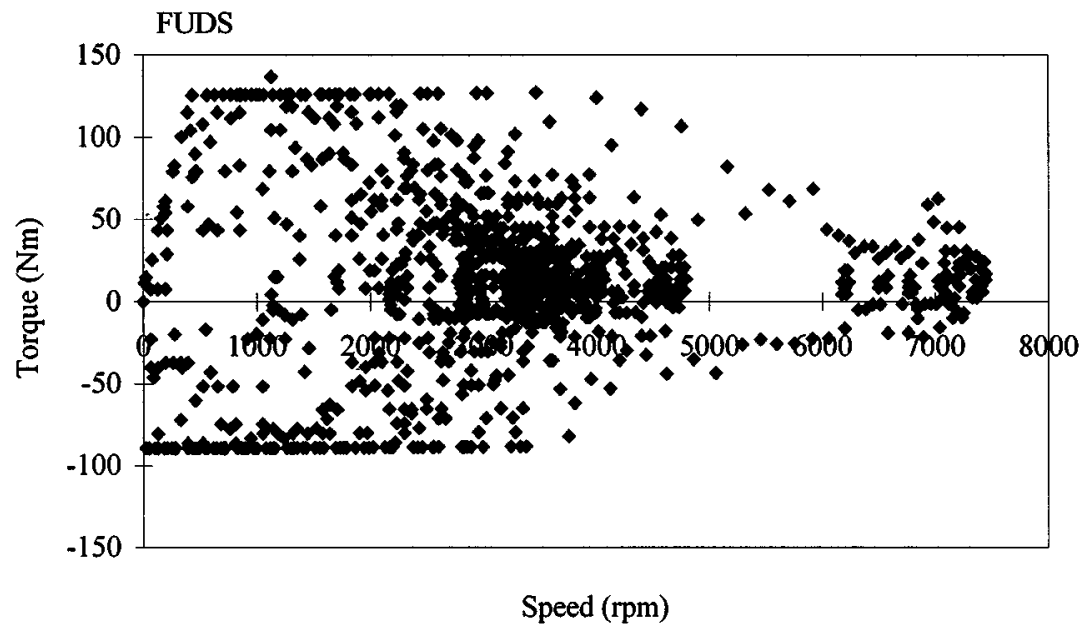

(a)

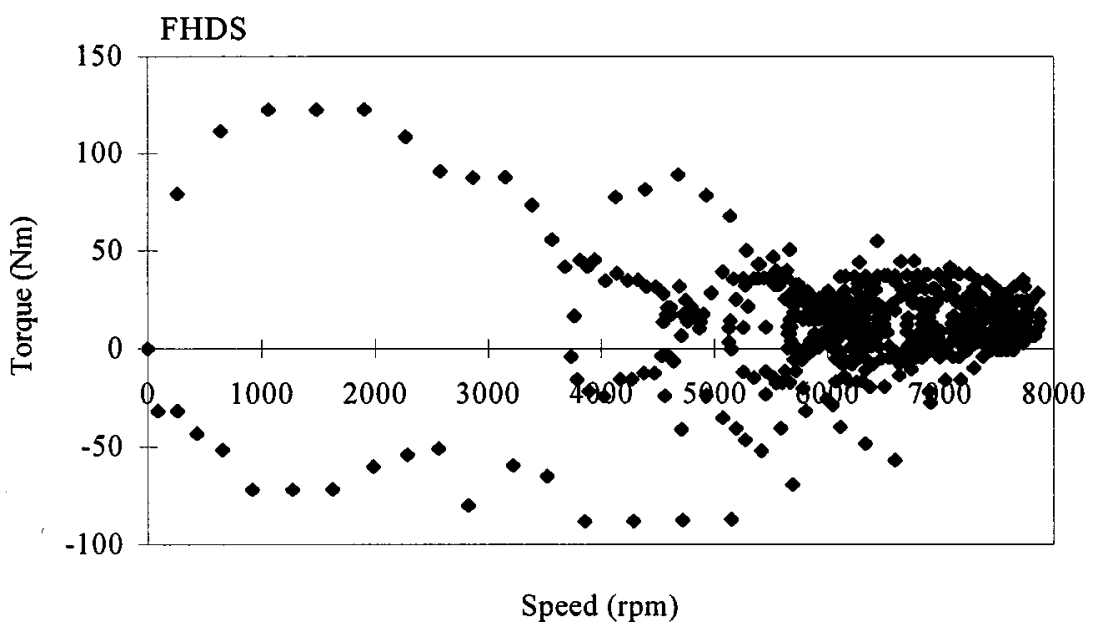

(b)

Fig. 13. Torque-speed requirements of typical driving cycles.

voltage, current) according to various driving cycles; for example, Fig. 13 shows that the torque-speed requirement of the Federal Urban Driving Schedule (FUDS) is very different from that of the Federal Highway Driving Schedule (FHDS). In Fig. 13, the density of dots represents the frequency of operating condition. Hence, in FUDS, the powertrain often operates at low speed and high torque, while in FHDS, it operates at a high-speed low-torque profile.

9) Adopt intelligent EMS.

10) Analyze the interaction of EV subsystems by using the quality function matrix as shown in Fig. 14, hence, understanding the degree of interaction that affects the cost, performance, and safety.

11) Optimize the efficiency of the motor drive according to the selected driving pattern and operating conditions.

12) Optimize the overall system using computer simulation.

\section{Key EV Technology}

The key technologies of EVs include automotive technology, electrical technology, electronic technology, information technology, and chemical technology. Although the energy source is the most crucial area, body design, electric propulsion, energy management, and system optimization are equally important. In fact, the integration of all these areas is the key to success. For ease of reading, only body design, energy management, and system optimization technologies are discussed in this section, while the major technologies of electric propulsion and energy source will be discussed separately in the subsequent sections.

1) Body Design: There are two basic approaches for producing EVs - either conversion or purpose-built. For the conversion $\mathrm{EV}$, the engine and associated equipment of an existing ICEV are replaced by the electric motor, power converter, and battery. This offers some economy for a small volume production because the existing ICEV chassis can be utilized. However, in most conversions, the resulting EV suffers from a greater curb weight, a higher centre of gravity and an unbalanced weight distribution. Therefore, this approach is gradually fading out. At present, the modern EVs are mostly purpose-built, sometimes called groundup design. This purpose-built EV takes the definite advantage over the conversion ones because they allow the engineers having the flexibility to coordinate and integrate various EV subsystems so that they can work together efficiently [17]. 


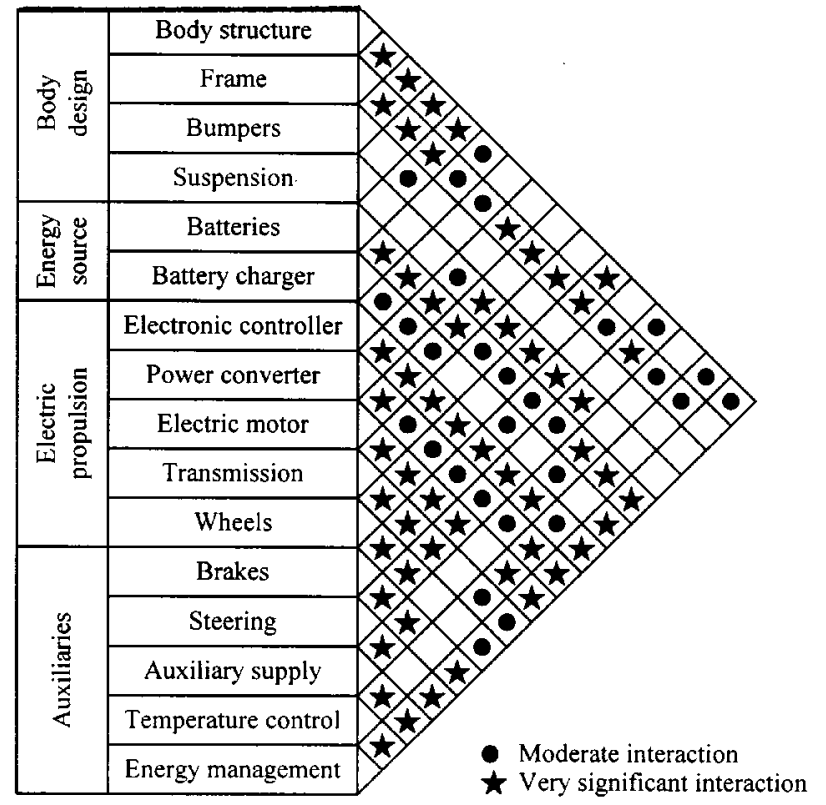

Fig. 14. Interactions among EV sybsystems.

There are some design concepts for purpose-built EVs so that the overall performances such as range, gradeability, acceleration, and top speed can be improved. These concepts include the consistent weight-saving design, low drag coefficient body design, and low rolling resistance concept. First, the vehicle weight directly affects the performance of EVs, especially the range and gradeability. To reduce the curb weight, the use of lightweight materials such as aluminum and composite material for the body and chassis can be adopted. Second, low drag coefficient body design can effectively reduce the vehicle aerodynamic resistance, which has a significant effect on extending the range of EVs in highway driving or cruising. In general, the aerodynamic resistance can be reduced by tapering front and rear ends, adopting undercover and flat underfloor design, optimizing airflow around the front and rear windows, using rear spats, providing airflow streaks along the front and rear tires, and employing slanted front nose design. Third, low rolling resistance tires are particularly effective in reducing running resistance at low and medium driving speeds and play an important role in extending the range of EVs in city driving. This can be achieved through the use of a newly developed blended tire polymer, together with an increase in tire pressure.

2) Energy Management: Compared with ICEVs, EVs offer a relatively short driving range. Thus, in order to maximize the utilization of onboard stored energy, an intelligent EMS needs to be adopted. Making use of sensory inputs from various EV subsystems, including sensors for temperatures of outside and inside air, current, and voltage of the energy source during charging and discharging, current and voltage of the electric motor, vehicle speed, and acceleration as well as external climate and environment, the EMS can realize the following functions.

1) Optimize the system energy flow.

2) Predict the remaining available energy and hence the residual driving range.
3) Suggest more efficient driving behavior.

4) Direct regenerative energy from braking to receptive energy sources such as batteries.

5) Modulate temperature control in response to external climate.

6) Adjust lighting brightness in response to external environment.

7) Propose a suitable battery charging algorithm.

8) Analyze the operation history of the energy source, especially the battery.

9) Diagnose any incorrect operation or defective components of the energy source.

When the EMS is coupled with a navigation system, it can plan energy efficient routes, locate charging facilities for extended trips, and modify range predictions on the basis of traffic conditions. In summary, the EMS has the distinct features of integrated multifunctions, flexibility, and adaptability (just like the brain of EVs) such that the limited onboard energy can be used wisely.

3) System Optimization: As mentioned before, the EV system has a complex architecture that contains multidisciplinary technologies. Since the EV performance can be affected by many multidisciplinary interrelated factors, computer simulation is the most important technology to carry out the optimization for performance improvement and cost reduction. Also, EV simulation can help those manufacturers to minimize prototyping cost and time and to provide rapid concept evaluation. Since the whole EV system consists of various subsystems clustered together by mechanical, electrical, control, and thermal links, the simulation should be based on the concept of mixed-signal simulation. Hence, the system optimization can be carried out in the system level in which there are many tradeoffs among various subsystem criteria. Generally, numerous iterative processes are involved for the preferred system criteria [1].

In summary, the system-level simulation and optimization of EVs should consider the following key issues.

1) As the interactions among various subsystems greatly affect the performance of EVs, the significance of those interactions should be analyzed and taken into account.

2) As the model accuracy is usually coherent with the model complexity but may be contradictory to the model usability, tradeoffs among the accuracy, complexity, and usability as well as simulation time should be considered.

3) As the system voltage generally causes contradictory issues for EV design, including the battery weight (higher voltage requires higher number of battery modules in series, hence more weight for the battery case), motor drive voltage and current ratings, acceleration performance, driving range and safety, it should be optimized on the system level.

4) In order to increase the driving range, multiple energy sources may be adopted for modern EVs. The corresponding combination and hybridization ratio should be optimized on the basis of the vehicle performance and cost. 


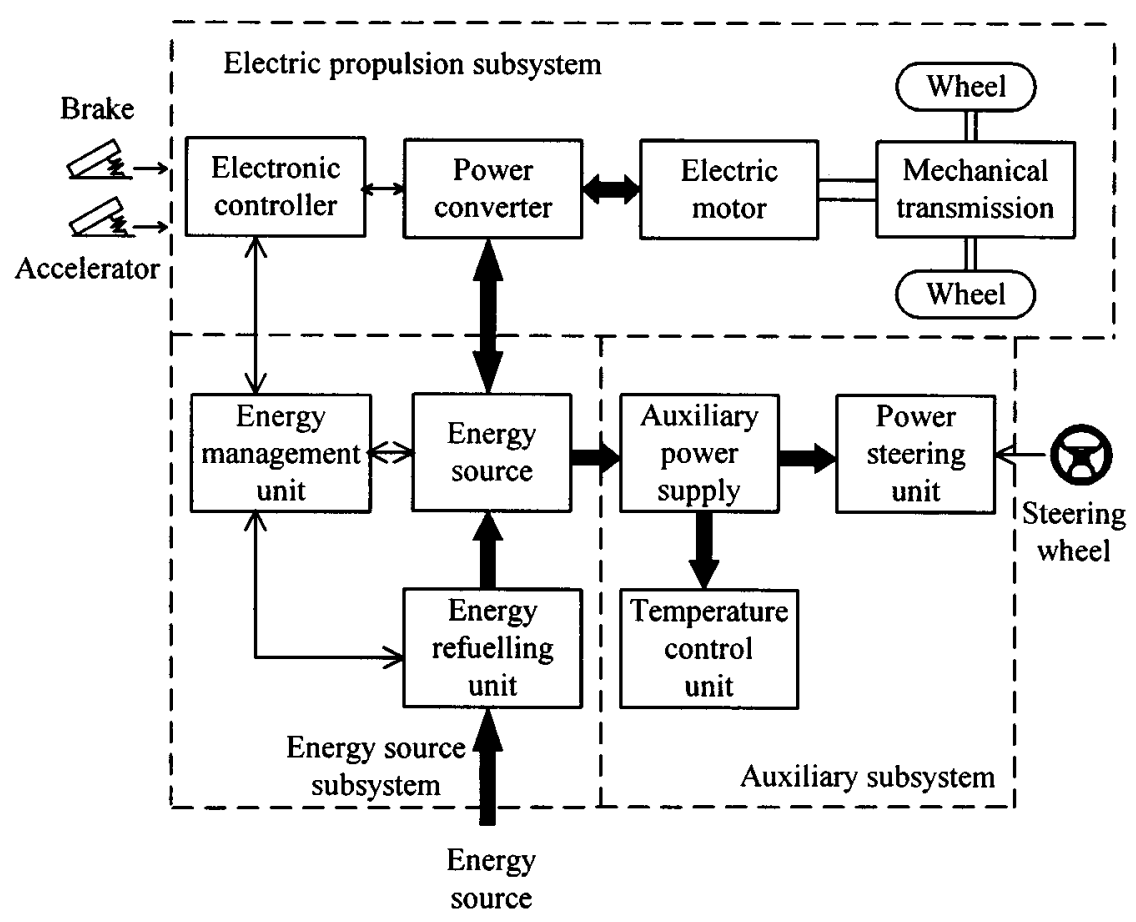

Fig. 15. EV composition.

5) Since EVs generally adopt fixed gearing, the gear ratio can greatly affect the vehicle performance and driveability. An optimal ratio should be determined through iterative optimization under different driving profiles.

\section{EV AND HEV CONFIGURATIONS}

\section{A. EV Configurations}

Compared with the ICEV, the configuration of the EV is rather flexible. This flexibility is due to several factors unique to the EV [1], [18]-[22]. First, the energy flow in the EV is mainly via flexible electrical wires rather than rigid and mechanical links. Thus, the concept of distributed subsystems in the EV is really achievable. Second, different EV propulsion arrangements involve a significant difference in the system configuration. Third, different EV energy sources (such as batteries and FCs) have different characteristics and different refueling systems.

Fig. 15 shows the composition of the EV consisting of three major subsystems-electric propulsion, energy source, and auxiliary. The electric propulsion subsystem comprises the electronic controller, power converter, electric motor, mechanical transmission, and driving wheels. The energy source subsystem involves the energy source, energy management unit, and energy refuelling unit. The auxiliary subsystem consists of the power steering unit, temperature control unit, and auxiliary power supply. In Fig. 15, a mechanical link is represented by a double line, an electrical link by a thick line, and a control link by a thin line. The arrow on each line denotes the direction of electrical power flow or control information communication. Based on the control inputs from the brake and accelerator pedals, the electronic controller provides proper control signals to switch on or off the power devices of the power converter which functions to regulate power flow between the electric motor and energy source. The backward power flow is due to regenerative braking of the $\mathrm{EV}$ and this regenerative energy can be stored provided that the energy source is receptive. Notice that most available EV batteries (except some metal/air batteries) as well as CFs readily accept regenerative energy. The energy management unit cooperates with the electronic controller to control regenerative braking and its energy recovery. It also works with the energy refuelling unit to control refuelling and to monitor usability of the energy source. The auxiliary power supply provides the necessary power with different voltage levels for all EV auxiliaries, especially the temperature control and power steering units.

At present, there are many possible EV configurations due to the variations in electric propulsion and energy sources. Focusing on those variations in electric propulsion, there are six typical alternatives, as shown in Fig. 16.

1) Fig. 16(a) shows the first alternative which is a direct extension of the existing ICEV adopting longitudinal front-engine front-wheel drive. It consists of an electric motor, a clutch, a gearbox, and a differential. By incorporating both clutch and gearbox, the driver can shift the gear ratios and, hence, the torque going to the wheels. The wheels have high torque low speed in the lower gears and high-speed low-torque in the higher gears. The differential is a mechanical device which enables the wheels to be driven at different speeds when cornering - the outer wheel covering a greater distance than the inner wheel. This configuration was mostly used in conversion type of EVs to maximize utilization of existing components. 


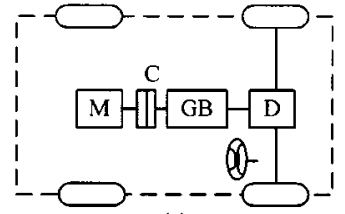

(a)

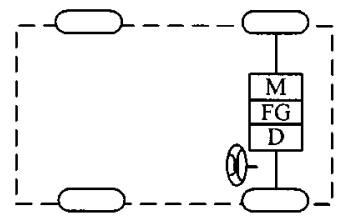

(c)

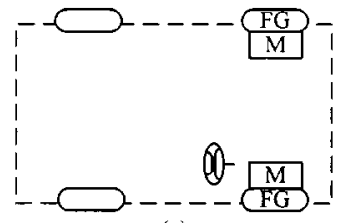

(e)

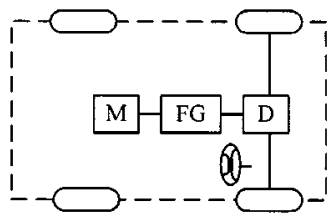

(b)

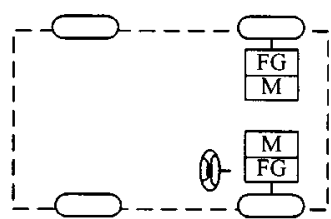

(d)

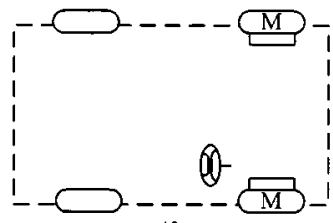

(f)

$$
\begin{aligned}
& \text { C : Clutch } \\
& \text { D : Differential } \\
& \text { FG : Fixed gearing } \\
& \text { GB : Gearbox } \\
& M \text { : Electric motor }
\end{aligned}
$$

Fig. 16. EV configuration due to variations in electric propulsion

2) By replacing the gearbox with fixed gearing and, hence, removing the clutch, both the weight and size of the mechanical transmission can be greatly reduced. Fig. 16(b) shows this arrangement, which consists of an electric motor, fixed gearing, and a differential. Notice that this EV configuration is not suitable for the ICEV as the engine by itself, without the clutch and gearbox, cannot offer the desired torque-speed characteristics.

3) Similar to the concept of transverse front-engine front-wheel drive of the existing ICEV, the electric motor, fixed gearing, and differential are integrated into a single assembly, while both axles point at both driving wheels. Fig. 16(c) show this configuration, which is, in fact, most commonly adopted by modern EVs.

4) Besides the mechanical means, the differential action of an EV when cornering can be electronically provided by two electric motors operating at different speeds. Fig. 16(d) shows this dual-motor configuration in which two electric motors separately drive the driving wheels via fixed gearing.

5) In order to further shorten the mechanical transmission path from the electric motor to the driving wheel, the electric motor can be placed inside a wheel. This arrangement is the so-called inwheel drive. Fig. 16(e) shows this configuration in which fixed planetary gearing is employed to reduce the motor speed to the desired wheel speed. It should be noted that planetary gearing is favored in this arrangement since it offers the advantages of a high-speed reduction ratio as well as an inline arrangement of input and output shafts.
6) By fully abandoning any mechanical gearing, the inwheel drive can be realized by installing a low-speed outer rotor electric motor inside a wheel. Fig. 16(f) shows this gearless arrangement in which the outer rotor is directly mounted on the wheel rim. Thus, speed control of the electric motor is equivalent to the control of the wheel speed and, hence, the vehicle speed.

The selection of the above configurations mainly depends on the size and application of EVs, the major criteria for selection are compactness, performance, weight, and cost. Presently, the popular configurations are Fig. 20(b) or (c), where configuration Fig. 20(e) or (f) have been used for demonstration or small scale production.

\section{B. HEV Configurations}

What exactly is an HEV? The definition available is so general that it anticipates future technologies of energy sources. As proposed by Technical Committee 69 (Electric Road Vehicles) of the International Electrotechnical Commission, an $\mathrm{HEV}$ is a vehicle in which propulsion energy is available from two or more kinds or types of energy stores, sources, or converters and at least one of them can deliver electrical energy. Based on this general definition, there are many types of HEVs, such as the gasoline ICE and battery, diesel ICE and battery, battery and FC, battery and capacitor, battery and flywheel, and battery and battery hybrids. However, the above definition is not well accepted. Ordinary people have already borne in mind that an HEV is simply a vehicle having both an ICE and electric motor. To avoid confusing readers or customers, specialists also prefer not using the HEV to represent a vehicle adopting energy source combinations other than the ICE and battery hybrid. For example, they prefer to call a battery and FC HEV simply as an FCEV and a battery and capacitor HEV as an ultracapacitor-assisted EV. As we prefer general perception to loose definition, the term $\mathrm{HEV}$ in this paper refers only to the vehicle adopting the ICE and electric motor.

The major challenges for HEV design are managing multiple energy source, which is highly dependent on driving cycles, battery sizing, and battery management. HEV can meet customers' need, but cost is the major issue. Therefore, with some incentives from governments to reduce initial cost burden, HEV may have substantial share in mainstream automobile production.

Traditionally, HEVs were classified into two basic kinds-series and parallel. Recently, with the introduction of some HEVs offering the features of both the series and parallel hybrids, the classification has been extended to three kinds - series, parallel, and series parallel. It is interesting to note that some newly introduced HEVs cannot be classified into these three kinds. Hereby, HEVs are newly classified into four kinds:

1) series hybrid;

2) parallel hybrid;

3) series-parallel hybrid;

4) complex hybrid. 


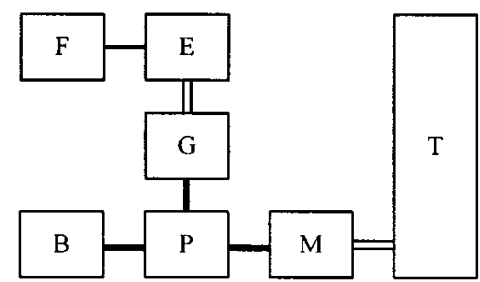

(a)

Series-parallel hybrid

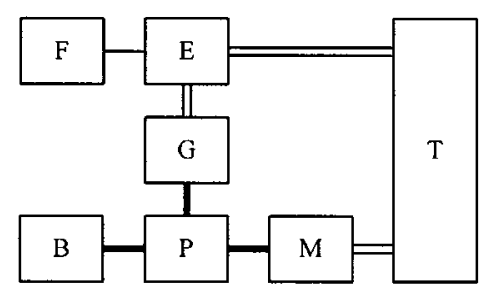

(c)

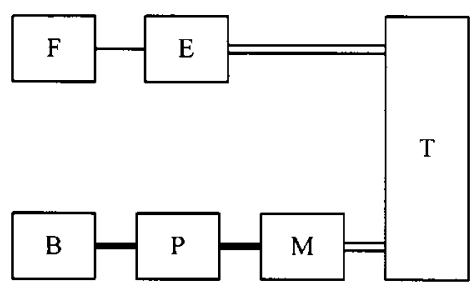

(b)

Complex hybrid

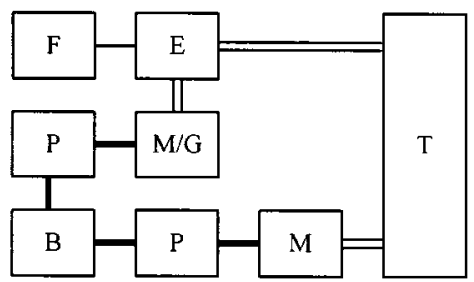

(d)

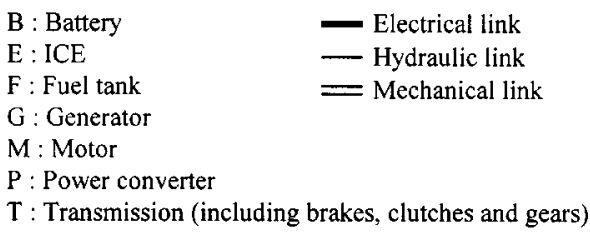

Fig. 17. Classification of HEVs.

Fig. 17 shows the corresponding functional block diagrams in which the electrical link is bidirectional, the hydraulic link is unidirectional, and the mechanical link (including the clutches and gears) is also bidirectional. It can be found that the key feature of the series hybrid is to couple the ICE with the generator to produce electricity for pure electric propulsion, whereas the key feature of the parallel hybrid is to couple both the ICE and electric motor to propel the wheels. The series-parallel hybrid is a direct combination of both the series and parallel hybrids. On top of the series-parallel hybrid operation, the complex hybrid can offer additional and versatile operating modes.

1) Series Hybrid System: The series hybrid is the simplest kind of HEV. Its ICE mechanical output is first converted into electricity using a generator. The converted electricity either charges the battery or can bypass the battery to propel the wheels via the same electric motor and mechanical transmission. Conceptually, it is an ICE-assisted EV that aims to extend the driving range comparable with that of the ICEV. Due to the decoupling between the engine and the driving wheels, it has the definite advantage of flexibility for locating the ICE generator set. Although it has an added advantage of simplicity of its drivetrain, it needs three propulsion devices, the generator, and the electric motor. Therefore, the efficiency of series HEV is generally lower. Another disadvantage is that all these propulsion devices need to be sized for the maximum sustained power if the series HEV is designed to climb a long grade, making series HEV expensive. On the other hand, when it is only needed to serve such short trips as commuting to work and shopping, the corresponding ICE generator set can adopt a lower rating.
2) Parallel Hybrid System: Differing from the series hybrid, the parallel HEV allows both the ICE and electric motor to deliver power in parallel to drive the wheels. Since both the ICE and electric motor are generally coupled to the drive shaft of the wheels via two clutches, the propulsion power may be supplied by the ICE alone, by the electric motor or by both. Conceptually, it is inherently an electric-assisted ICEV for achieving lower emissions and fuel consumption. The electric motor can be used as a generator to charge the battery by regenerative braking or absorbing power from the ICE when its output is greater than that required to drive the wheels. Better than the series HEV, the parallel hybrid needs only two propulsion devices - the ICE and the electric motor. Another advantage over the series case is that a smaller ICE and a smaller electric motor can be used to get the same performance until the battery is depleted. Even for long-trip operation, only the ICE needs to be rated for the maximum sustained power while the electric motor may still be about a half.

3) Series-Parallel Hybrid System: In the series-parallel hybrid, the configuration incorporates the features of both the series and parallel HEVs, but involving an additional mechanical link compared with the series hybrid and also an additional generator compared with the parallel hybrid. Although possessing the advantageous features of both the series and parallel HEVs, the series-parallel HEV is relatively more complicated and costly. Nevertheless, with the advances in control and manufacturing technologies, some modern HEVs prefer to adopt this system.

4) Complex Hybrid System: As reflected by its name, this system involves a complex configuration that cannot be clas- 


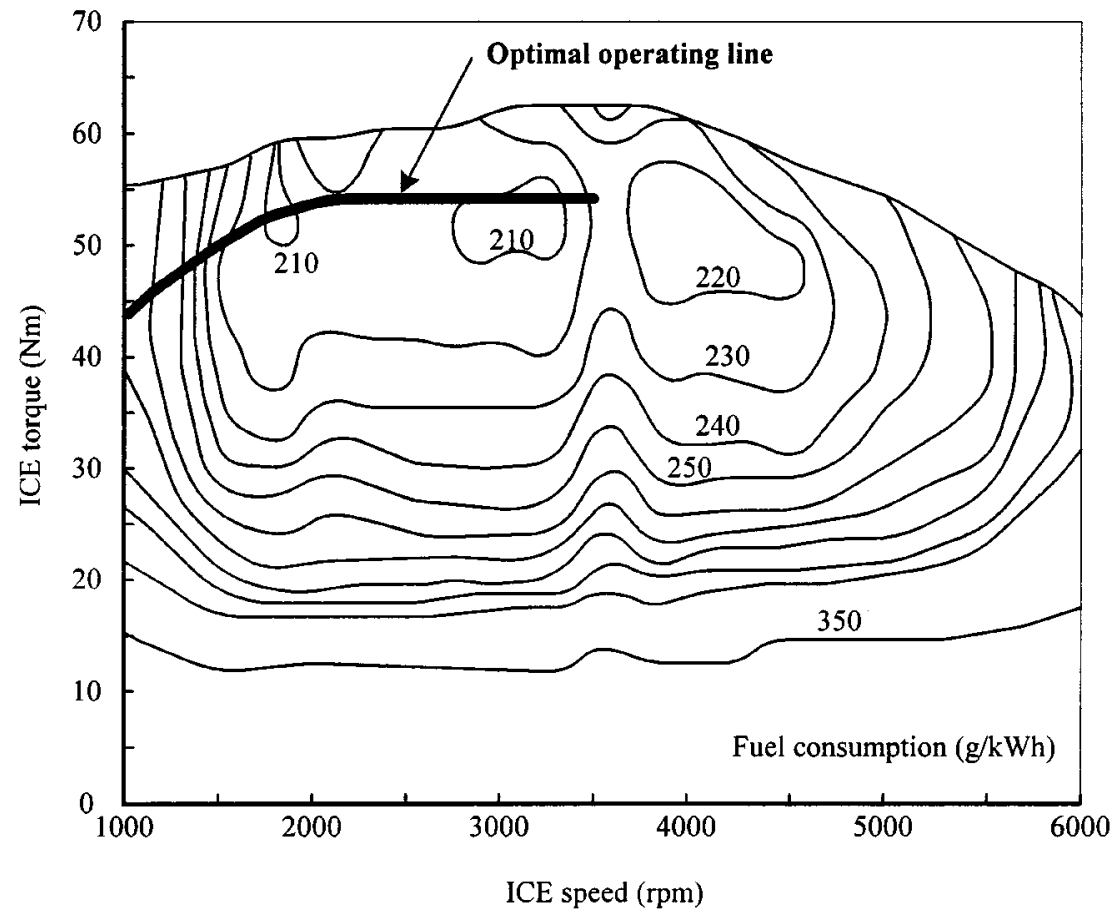

Fig. 18. Optimal operating line on an ICE fuel consumption map.

sified into the above three kinds. As shown in Fig. 17(d), the complex hybrid seems to be similar to the series-parallel hybrid, since the generator and electric motor are both electric machinery. However, the key difference is due to the bidirectional power flow of the electric motor in the complex hybrid and the unidirectional power flow of the generator in the series-parallel hybrid. This bidirectional power flow can allow for versatile operating modes, especially the three propulsion power (due to the ICE and two electric motors) operating mode, which cannot be offered by the series-parallel hybrid. Similar to the series-parallel HEV, the complex hybrid suffers from higher complexity and costliness. Nevertheless, some newly introduced HEVs adopt this system for dual-axle propulsion.

5) Power Flow Control: Due to the variations in HEV configurations, different power-control strategies are necessary to regulate the power flow to or from different components. These control strategies aim to satisfy a number of goals for HEVs. There are four key goals:

1) maximum fuel economy;

2) minimum emissions;

3) minimum system costs;

4) good driving performance.

The design of power-control strategies for HEVs involves different considerations. Some key considerations are summarized below.

1) Optimal ICE Operating Point: The optimal operating point on the torque-speed plane of the ICE can be based on the maximization of fuel economy, the minimization of emissions, or even a compromise between fuel economy and emissions.

2) Optimal ICE Operating Line: In case the ICE needs to deliver different power demands, the corresponding optimal operating points constitute an optimal operating line. Fig. 18 shows a typical optimal operating line of an ICE in which the optimization is based on the minimum fuel consumption, which is equivalent to the maximum fuel economy.

3) Optimal ICE operating Region: The ICE has a preferred operating region on the torque-speed plane in which the fuel efficiency remains optimum.

4) Minimum ICE Dynamics: The ICE operating speed needs to be regulated in such a way that any fast fluctuations are avoided, hence minimizing the ICE dynamics.

5) Minimum ICE Speed: When the ICE operates at low speeds, the fuel efficiency is very low. The ICE should be cut off when its speed is below a threshold value.

6) Minimum ICE Turnon Time: The ICE should not be turned on and off frequently; otherwise, it results in additional fuel consumption and emissions. A minimum turnon time should be set to avoid such drawbacks.

7) Proper Battery Available: The battery-available capacity needs to be kept at a proper level so that it can provide sufficient power for acceleration and can accept regenerative power during braking or downhill. When the battery-available capacity is too high, the ICE should be turned off or operated idly. When the available capacity is too low, the ICE should increase its output to charge the battery as fast as possible.

8) Safety Battery Voltage: The battery voltage may be significantly altered during discharging, generator charging, or regenerative charging. This battery voltage should not be overvoltage or undervoltage; 


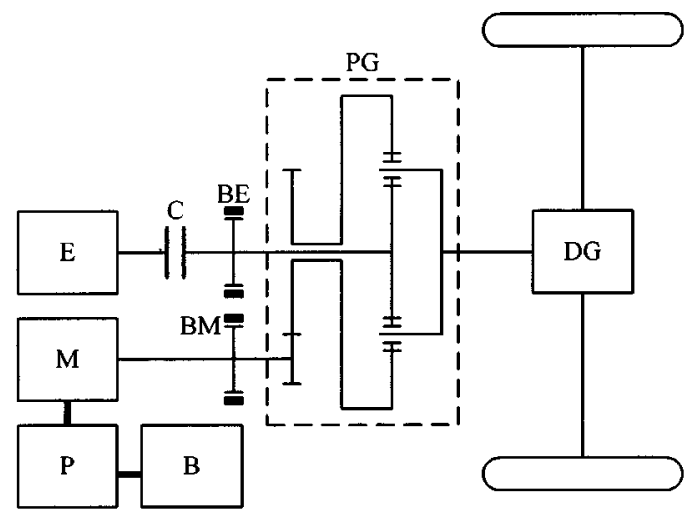

B: Battery
BE: Brake of engine shaft $\quad$ Electrical link
BM: Brake of motor shaft
C: Clutch
E: ICE
DG: Differential gear
M: Motor
P: Power converter
PG: Planetary gear

Fig. 19. New HEV system with planetary gear (courtesy of a A. Szumonowski).

otherwise, the battery may be permanently damaged. Therefore, battery management is a critical issue.

9) Relative Distribution: The distribution of power demand between the ICE and battery can be optimized during the driving cycle.

10) Geographical Policy: In certain cities or areas, the $\mathrm{HEV}$ needs to be operated in the pure electric mode. The changeover should be controlled manually or automatically.

6) Advanced HEV System Performance: Fig. 19 shows a new parallel hybrid HEV system. This HEV system not only possesses the features of the parallel hybrid, but also incorporates a unique advantage of the series hybrid (namely, the ICE can independently operate at the mode of minimum fuel consumption). The key is to employ a planetary gear that offers two degrees of freedom for mechanical transmission.

In city driving, the HEV system is characterized by the features of a parallel hybrid and the advantage of a series hybrid. When the vehicle is at full-throttle acceleration, the power is simultaneously delivered by the ICE and electric motor. While the vehicle at normal driving (steady speed operation), the power is collaboratively fed by the ICE and electric motor via the planetary gear with two degrees of freedom in such a way that the fuel consumption of the ICE is minimum. This means that the ICE operates at minimum torque and power and the majority of power is supplied by the electric motor.

During regenerative braking, the planetary gear operation is reduced to one degree of freedom by disconnecting the clutch and braking the sun gear shaft. Thus, the kinetic energy is converted to electrical energy and, hence, recharges the battery while the electric motor operates as an generator.

During suburb driving, the HEV operates as an ICEV. In this case, the electric motor is switched off and the ring gear shaft is braked, which means that the planetary gear operation is also reduced to one degree of freedom.

The power distribution using planetary gearing provides the merits of significant torque and power stabilization of ICE operation, hence achieving high efficiency of the whole HEV system. Fig. 20 shows the simulated performances of this new HEV system and gives comparative results under the driving cycles of FUD 48 (maximum steady speed at 48 $\mathrm{km} / \mathrm{h}$ ) and FUD 72 (maximum steady speed at $72 \mathrm{~km} / \mathrm{h}$ ). It can be seen from Fig. 24(d) that the discharge factor (state of charge) is about the same at the beginning and end of cycle, which implies minimum energy consumption of both the battery and ICE.

\section{ELECTRIC PROPULSION}

\section{A. General Consideration}

The electric propulsion system is the heart of EV [23]-[39]. It consists of the motor drive, transmission device, and wheels. The transmission device sometimes is optional. In fact, the motor drive, comprising of the electric motor, power converter, and electronic controller, is the core of the EV propulsion system. The major requirements of the $\mathrm{EV}$ motor drive are summarized as follows.

1) High instant power and high power density.

2) High torque at low speeds for starting and climbing, as well as high power at high speed for cruising.

3) Very wide speed range including constant-torque and constant-power regions.

4) Fast torque response.

5) High efficiency over wide speed and torque ranges.

6) High efficiency for regenerative braking.

7) High reliability and robustness for various vehicle operating conditions.

8) Reasonable cost.

The choice of electric propulsion systems for EVs mainly depends on three factors-driver expectation, vehicle constraint and energy source. The driver expectation is defined by a driving profile which includes the acceleration, maximum speed, climbing capability, braking, and range. The vehicle constraint depends on the vehicle type, vehicle weight, and payload. The energy source relates with batteries, FCs, capacitors, flywheels, and various hybrid sources. Thus, the process of identifying the preferred features and packaging options for electric propulsion has to be carried out at the system level. The interactions between subsystems and those likely impacts of system tradeoffs must be examined.

The development of electric propulsion systems has been based on the growth of various technologies, especially electric motors, power electronics, microelectronics, and control strategies. Fig. 21 shows EV propulsion system overview, including the possible types of motor, computer-aided design (CAD) methodology, power converter devices/topology, control hardware, software, and strategy. Toady, with regards to motor technology, CAD finite-element method analyzed IMs and PM brushless motors are most favorable. With regard to power converter technology, 

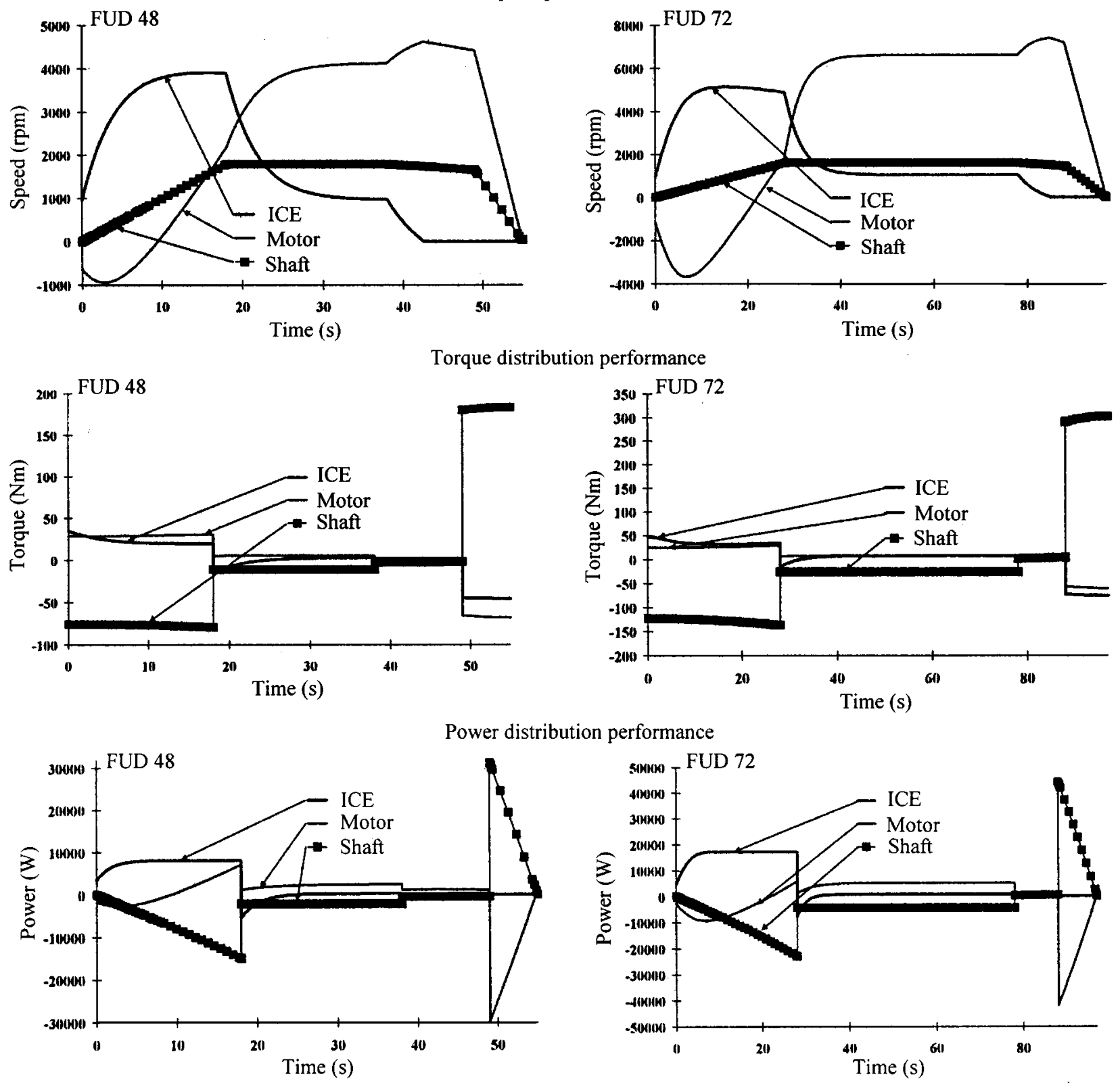

Battery discharge factor performance
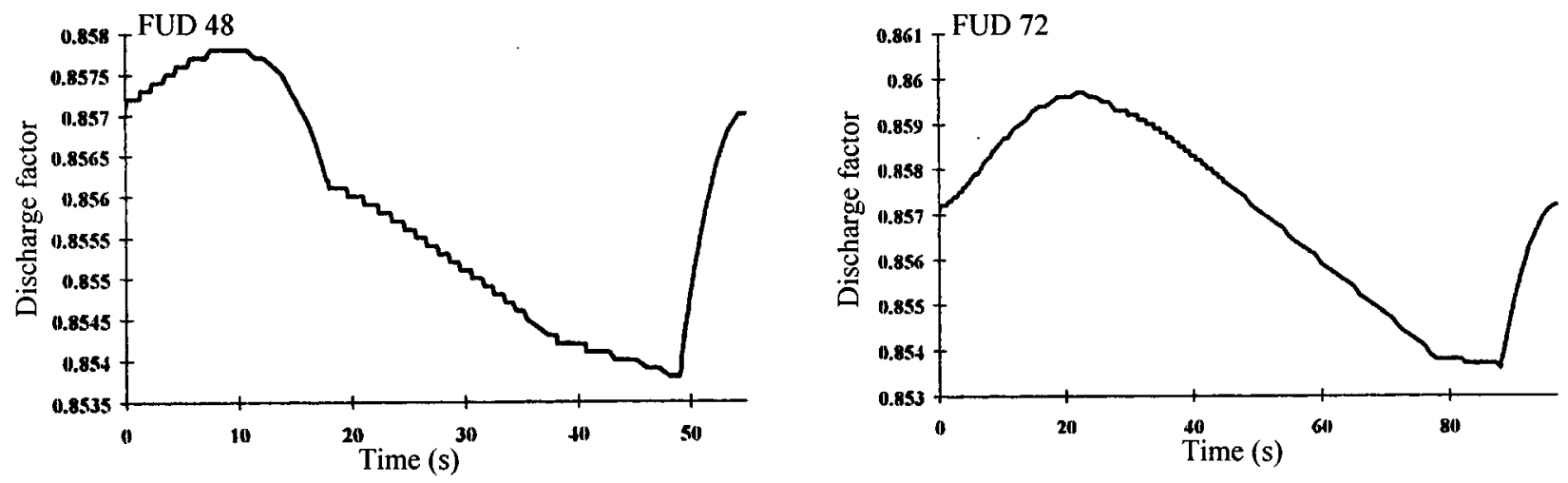

Fig. 20. Performance of a new HEV system (courtesy of a A. Szumanowski).

pulse-width modulation/insulated-gate bipolar transistor inverters are the most popular. With regard to control tech- nology, microprocessor, or digital-signal-processor-based vector controls are very common. 


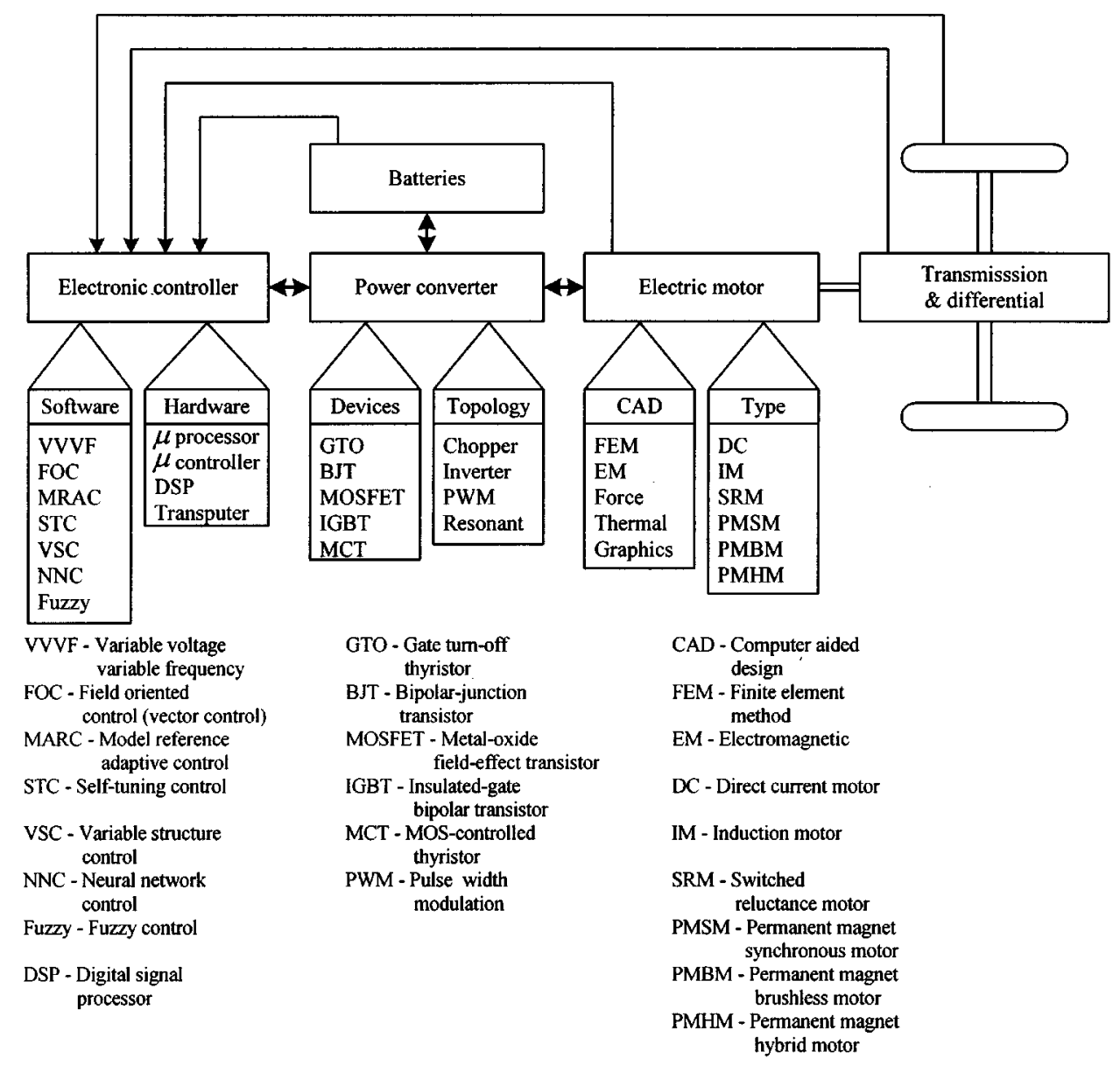

Fig. 21. EV propulsion system overview.

Traditionally, DC motors have ever been prominent in electric propulsion because their torque-speed characteristics suit traction requirement well and their speed controls are simple. However, the DC motor has a commutator; hence, it requires regular maintenance. Recently, technological developments have pushed commutatorless motors to a new era, leading with the advantages of higher efficiency, higher power density, lower operating cost, more reliability, and lower maintenance over DC motors. As high reliability and maintenance-free operation are prime considerations for electric propulsion in EVs, commutatorless motors are becoming attractive. IMs are a widely accepted commutatorless motor type for EV propulsion because of they are mature, highly reliable, and free from maintenance. Alternatively, PM brushless motors are also promising because they use PM to produce the magnetic field. Hence, higher efficiency and higher power density can be achieved. SR motors also have potential because their simple and robust construction. Table 4 shows the application of different types motors for major EVs. The evaluation of EV motors is shown in Table 5 in which a point grading system is adopted. The grading system consists of six major characteristics and each of them is graded from one to five points, where five points means the best. It can be seen that IM drives and PM brushless motor drives are the main stream in today's EV electric propulsion, which are consistent with the survey mentioned in Section III-C.
Table 4

Applications of EV Motors

\begin{tabular}{ll}
\hline EV models & EV motors \\
\hline Fiat Panda Elettra & Series dc motor \\
Mazda Bongo & Shunt dc motor \\
Conceptor G-Van & Separately excited dc motor \\
Suzuki Senior Tricycle & PM dc motor \\
Fiat Seicento Elettra & Induction motor \\
Ford Th!nk City & Induction motor \\
GM EV1 & Induction motor \\
Honda EV Plus & PM brushless motor \\
Nissan Altra & PM brushless motor \\
Toyota RAV4 & PM brushless motor \\
Chloride Lucas & Switched reluctance motor \\
\hline
\end{tabular}

\section{B. Vector-Controlled Induction Motor Drives}

Today, IM drive is the most mature technology among various commutatorless motor drives. Fig. 22 shows the characteristics of IM drives. In order to improve the dynamic performance of IM drives for EV propulsion, vector control is preferred. Although vector control may offer wide speed range up to three to four times of base speed, but the efficiency at high-speed range may suffer. Fig. 23 shows the efficiency optimizing of vector controlled IM drive for EVs [38]. This control scheme is able to control the torque component current and field component current hence to minimize the total losses at any loading condition. 


\begin{tabular}{llllll}
\hline & $\begin{array}{l}\text { DC } \\
\text { motor }\end{array}$ & $\begin{array}{l}\text { Induction } \\
\text { motor }\end{array}$ & $\begin{array}{l}\text { PM brushless } \\
\text { motor }\end{array}$ & $\begin{array}{l}\text { SR } \\
\text { motor }\end{array}$ & $\begin{array}{l}\text { PM hybrid } \\
\text { motor }\end{array}$ \\
\hline Power density & 2.5 & 3.5 & 5 & 3.5 & 4 \\
Efficiency & 2.5 & 3.5 & 5 & 3.5 & 5 \\
Controllability & 5 & 4 & 4 & 3 & 4 \\
Reliability & 3 & 5 & 4 & 5 & 4 \\
Maturity & 5 & 5 & 4 & 4 & 3 \\
Cost & 4 & 5 & 3 & 4 & 3 \\
Total & $\mathbf{2 2}$ & $\mathbf{2 6}$ & $\mathbf{2 5}$ & $\mathbf{2 3}$ & $\mathbf{2 3}$ \\
\hline
\end{tabular}

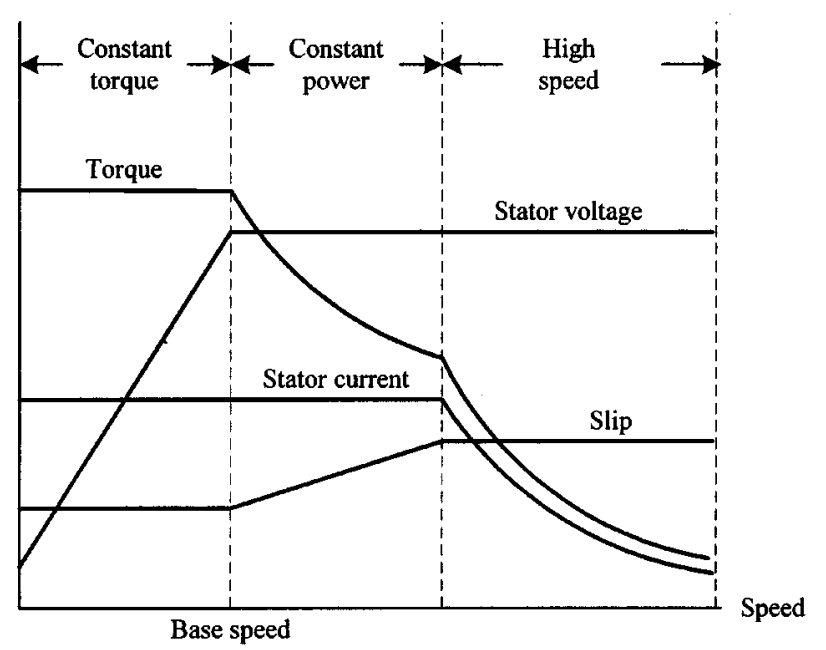

Fig. 22. Characteristics of IM drives.

\section{PM Brushless Motor Drives}

Among those modern motor drives, PM brushless motor drives are most capable of competing with IM drives for electric propulsion. Their advantages are summarized as follows.

1) Since the magnetic field is excited by high-energy PMs, the overall weight and volume can be significantly reduced for a given output power, leading to higher power density.

2) Because of the absence of rotor copper losses, their efficiency is inherently higher than that of IMs.

3) Since the heat mainly arises in the stator, it can be more efficiently dissipated to surroundings.

4) Since PM excitation suffers from no risk of manufacturing defects, overheating, or mechanical damage, their reliability is inherently higher.

5) Because of lower electromechanical time constant of the rotor, the rotor acceleration at a given input power can be increased

In order to increase the speed range and improve the efficiency of PM brushless motor, the conduction angle of the power converter can be controlled at above the base speed. Fig. 24 shows the torque-speed characteristic of a PM brushless motor with conduction angle control. The speed range may reach three to four times of base speed. However, at very high-speed range the efficiency may drops, the PM may suffer from demagnetization and possible fault.

There are various configurations of PM brushless motors. Depending on the arrangement of the PM, basically they can be classified as surface magnet mounted or buried magnet mounted. The surface magnet designs may use less magnet, while the buried magnet designs may achieve higher air-gap flux density. The most commonly used PM is neodymium-iron boron. Another configuration is so called PM hybrid motor, where the air-gap magnetic field is obtained through the combination of PM and field winding. In the broader term, PM hybrid motor may also include the motor whose configuration utilize the combination of PM motor and reluctance motor. PM hybrid motors offer wider speed range and higher overall efficiency but more complex construction.

\section{SR Motor Drives}

SR motors have been recognized to have potential for EV applications. Basically, they are direct derivatives of single-stack variable-reluctance stepping motors. SR motors have the definite advantages of simple construction, low manufacturing cost, and outstanding torque-speed characteristics for EV propulsion. Although they possess the simplicity in construction, it does not imply any simplicity of their design and control. Because of the heavy saturation of pole tips and the fringe effect of poles and slots, their design and control are difficult and subtle. Also, they usually exhibit acoustic noise problems. Recently, an optimum design approach to SR motors has been developed [29], which employs finite element analysis to minimize the total motor losses while taking into account the constraints of pole arc, height, and maximum flux density. Also, fuzzy sliding mode control has been developed for those EV SR motors so as to handle the motor nonlinearities and minimize the control chattering [39].

\section{ENERGY SOURCES}

\section{A. General Consideration}

The EV energy source has been identified to be the major obstacle of EV commercialization [40]-[51], [66]. Thus, the present and foreseeable future most important EV development issue is how to develop various EV energy sources. Those development criteria are summarized as follows:

1) high specific energy $(\mathrm{kWh} / \mathrm{kg})$ and energy density $(\mathrm{kWh} / \mathrm{L})$;

2) high specific power $(\mathrm{kWh} / \mathrm{kg})$ and power density $(\mathrm{kW} / \mathrm{L})$;

3) fast-charging and deep-discharging capabilities; 


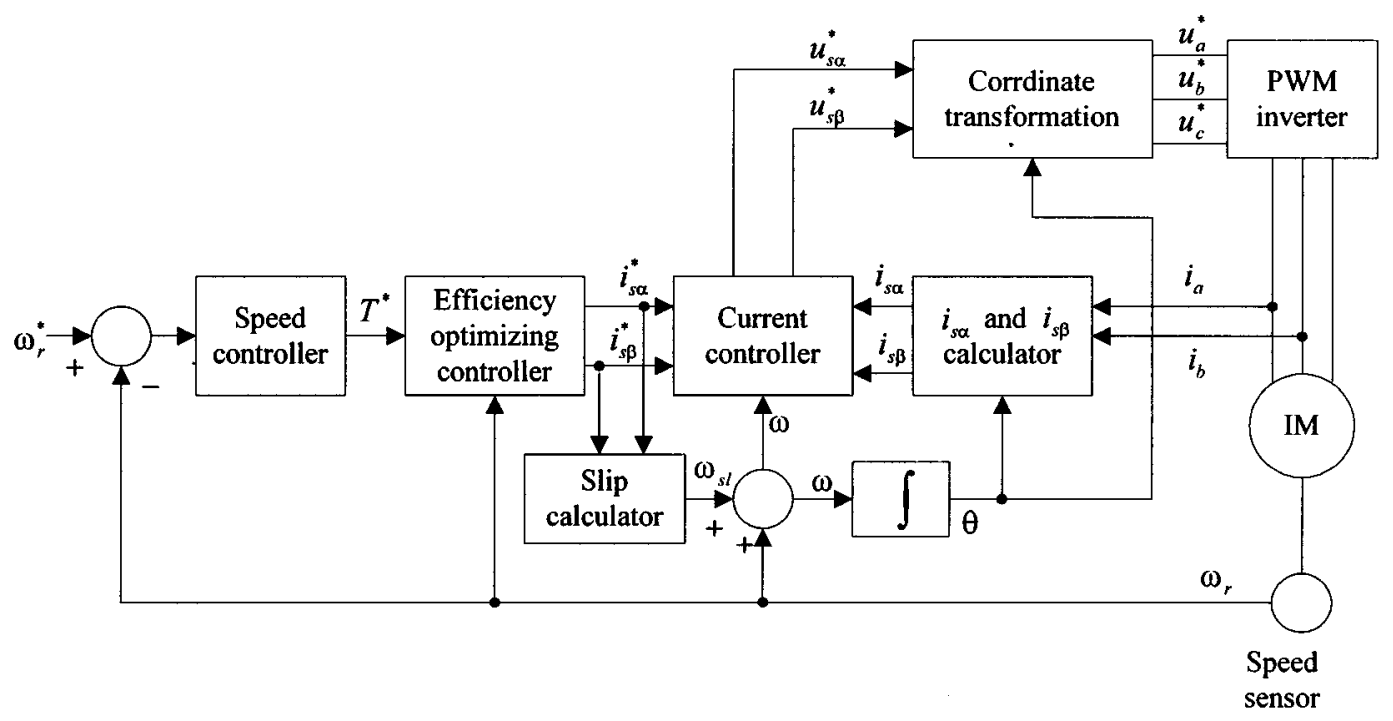

Fig. 23. Efficiency optimizing vector controlled EV IM drive.

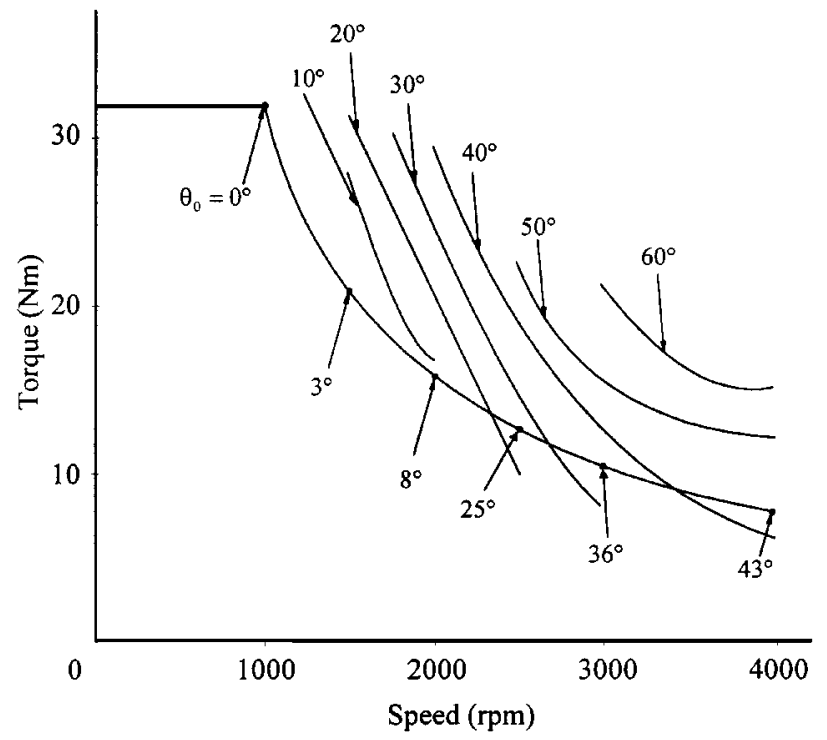

Fig. 24. Torque-speed characteristics of a PM brushless motor drive with conduction angle control.

4) long cycle and service lives.

5) self-discharging rate and high-charging efficiency;

6) safety and cost effectiveness;

7) maintenance-free;

8) environmentally sound and recyclable.

Rather than based on one energy source, the use of multiple energy sources, the so-called hybridization of energy sources, can eliminate the compromise between the specific energy and specific power. For the hybridization of two energy sources, one is selected for high specific energy while the other for high specific power. For examples, there are the battery and battery hybrid, battery and ultracapacitor hybrid, battery and ultra high-speed flywheel hybrid (flywheel is still in the research stage; major issues include safety, complexity, and weight), and FC and battery hybrid. In fact, the HEV is a special case of this hybridization, namely, the gasoline is of high specific energy for the long driving range while the bat- tery is of high specific power for assisting fast acceleration and providing emission-free operation.

\section{B. Batteries}

At the present time and in the foreseeable future, batteries have been agreed to be the major energy source for EVs. The U.S. Advanced Battery Consortium (USABC), which is the organization formed in the United States by the Department of Energy, the Electric Power Research Institute, Ford, General Motors, Chrysler, and the battery manufacturers to fund research on advanced battery technology, has set the midterm and long-term performance goals of EV batteries. As summarized in Table 6, these performance goals for EV batteries are very demanding ones and it is obvious that no existing battery technology is capable of meeting all these criteria because the USABC aims to make an EV as close in performance to an ICEV as possible.

Those viable EV batteries consist of the VRLA, Ni-Cd, nickel-zinc (Ni-Zn), Ni-MH, Zn/Air, aluminum/air (Al/Air), sodium/sulphur $(\mathrm{Na} / \mathrm{S})$, sodium/nickel chloride $\left(\mathrm{Na} / \mathrm{NiCl}_{2}\right)$, lithium-polymer (Li-Polymer), and Li-Ion types.

Detailed chemistries of the aforementioned batteries can be found in relevant battery handbooks [49]. Some of their important parameters, including specific energy, energy density, specific power, cycle life, and projected cost with respect to the USABC's goals, are shown in Table 7. It should be noted that these parameters are only for indicative purposes since the data may have wide variations among different battery manufacturers. Even for the same manufacturer, different models of the same battery may also have significant variations because of different tradeoffs among the specific energy, specific power, and cycle life. Moreover, these data always change with the advancement of battery technology. From Table 7, it can be found that none of them can fully satisfy the USABC's long-term goals, which aim to enable EVs directly competing with ICEVs.

Nevertheless, in order to meet the California mandate of $10 \%$ zero-emission vehicles by 2003 , the development of 
Table 6

Performance Goals of USABU

\begin{tabular}{|c|c|c|}
\hline Primary goals & Mid-term & Long-term \\
\hline Specific energy ( $C / 3$ discharge rate $)(\mathrm{Wh} / \mathrm{kg})$ & $80(100$ desired $)$ & 200 \\
\hline Energy density ( $C / 3$ discharge rate) $(\mathrm{Wh} / \mathrm{l})$ & 135 & 300 \\
\hline Specific power $(80 \%$ DOD $/ 30 \mathrm{~s})(\mathrm{W} / \mathrm{kg})$ & 150 (200 desired $)$ & 400 \\
\hline Power density $(\mathrm{W} / \mathrm{l})$ & 250 & 600 \\
\hline Life (years) & 5 & 10 \\
\hline Cycle life ( $80 \%$ DOD) (cycles) & 600 & 1000 \\
\hline Ultimate price (US\$/kWh) & $<150$ & $<100$ \\
\hline Operating temperature $\left({ }^{\circ} \mathrm{C}\right)$ & -30 to 65 & -40 to 85 \\
\hline Recharge time $(\mathrm{h})$ & $<6$ & 3 to 6 \\
\hline Fast recharge time ( 40 to $80 \%$ SOC) (h) & 0.25 & \\
\hline Secondary goals & & \\
\hline Efficiency $(C / 3$ discharge, $6 \mathrm{~h}$ charge $)(\%)$ & 75 & 80 \\
\hline Self-discharge $(\%)$ & $<15(48 \mathrm{~h})$ & $<15$ (month) \\
\hline Maintenance & \multicolumn{2}{|c|}{ no maintenance } \\
\hline Abuse resistance & \multicolumn{2}{|c|}{ tolerance } \\
\hline Thermal loss (for high-temperature batteries) & \multicolumn{2}{|c|}{$3.2 \mathrm{~W} / \mathrm{kWh}$} \\
\hline
\end{tabular}

Table 7

Key Parameters of EV Batteries

\begin{tabular}{|c|c|c|c|c|c|}
\hline & $\begin{array}{l}\text { Specific energy a } \\
(\mathrm{Wh} / \mathrm{kg})\end{array}$ & $\begin{array}{l}\text { Energy density } \\
(\mathrm{Wh} / \mathrm{l})\end{array}$ & $\begin{array}{l}\text { Specific power } \\
\text { (W/kg) }\end{array}$ & $\begin{array}{l}\text { Cycle life } \\
\text { (Cycles) }\end{array}$ & $\begin{array}{l}\text { Projected cost }{ }^{d} \\
\text { (US } \$ / k W h)\end{array}$ \\
\hline VRLA & $30-45$ & $60-90$ & $200-300$ & $400-600$ & 150 \\
\hline $\mathrm{Ni}-\mathrm{Cd}$ & $40-60$ & $80-110$ & $150-350$ & $600-1200$ & 300 \\
\hline $\mathrm{Ni}-\mathrm{Zn}$ & $60-65$ & $120-130$ & $150-300$ & 300 & $100-300$ \\
\hline Ni-MH & $60-70$ & $130-170$ & $150-300$ & $600-1200$ & $200-350$ \\
\hline $\mathrm{Zn} / \mathrm{Air}$ & 230 & 269 & 105 & $N^{c}{ }^{c}$ & $90-120$ \\
\hline $\mathrm{Al} / \mathrm{Air}$ & $190-250$ & $190-200$ & $7-16$ & $\mathrm{NA}^{\mathrm{c}}$ & NA \\
\hline $\mathrm{Na} / \mathrm{S}$ & 100 & 150 & 200 & 800 & $250-450$ \\
\hline $\mathrm{Na} / \mathrm{NiCl}_{2}$ & 86 & 149 & 150 & 1000 & $230-350$ \\
\hline Li-Polymer & 155 & 220 & 315 & 600 & NA \\
\hline Li-Ion & $90-130$ & $140-200$ & $250-450$ & $800-1200$ & $>200$ \\
\hline USABC & 200 & 300 & 400 & 1000 & $<100$ \\
\hline $\begin{array}{l}\text { NA: Not av } \\
\text { a At } C / 3 \text { rat } \\
\text { b At } 80 \% \text { D } \\
\text { c Mechanic } \\
\text { d For refere }\end{array}$ & $\begin{array}{l}\text { D } \\
\text { recharging } \\
\text { enly }\end{array}$ & & & & \\
\hline
\end{tabular}

EV batteries has to be continued and accelerated. Table 8 summarizes the key features, including advantages, disadvantages, and potentiality, of the aforementioned batteries. It can be found that those batteries with near-term high potentiality are the VRLA, Ni-Cd, and Ni-MH. Since the features of the Ni-MH are superior to those of the Ni-Cd, except maturity, the $\mathrm{Ni}-\mathrm{Cd}$ is being superseded by the Ni-MH. Actually, some manufacturers used to produce the $\mathrm{Ni}-\mathrm{Cd}$ for EV applications have redirected their efforts to the Ni-MH. Thus, in near term, the VRLA is still popular due to its maturity and cost effectiveness, whereas the Ni-MH is attractive because of its good performances. On the other hand, those batteries with midterm high potentiality include the Ni-Zn, $\mathrm{Zn} / \mathrm{Air}, \mathrm{Na} / \mathrm{NiCl}_{2}$, Li-Polymer, and Li-Ion. The Li-Ion has been identified by many battery manufacturers to be the most promising midterm EV battery. Its key obstacle is high initial cost, which should be greatly reduced upon mass production. The $\mathrm{Zn} /$ Air is also very promising because of its excellent specific energy and fast mechanical refuelling. However, this mechanically rechargeable battery cannot accept energy resulting from regenerative braking. Since the major drawback of the Ni-Zn, namely, short cycle life, is being alleviated in recent development, it may have the potential to compete with the Ni-MH in midterm. The $\mathrm{Na} / \mathrm{NiCl}_{2}$ is relatively the acceptable high-temperature battery for EV applications. It is promising in midterm provided that the battery performances can be further improved. The Li-Polymer has demonstrated to exhibit good performances for EV applications. It is promising in midterm provided that more battery manufacturers are involved to accelerate its research and development.

It should be noted that, in addition to the required performance of the batteries, the battery management system is also prime important to ensure the charging and discharging of batteries are in proper conditions. The replacement and recycling of batteries must also be taken care.

\section{Fuel Cells}

The FC is an electrochemical device that converts the free-energy change of an electrochemical reaction into 
Table 8

Key Features of EV Batteries

\begin{tabular}{|c|c|c|}
\hline & Key advantages / disadvantages for EV applications & Potentiality \\
\hline VRLA & $\begin{array}{l}\text { mature, low cost, fast rechargeable, high specific power / } \\
\text { low specific energy }\end{array}$ & $\begin{array}{l}\text { near-term } \\
\text { very high }\end{array}$ \\
\hline $\mathrm{Ni}-\mathrm{Cd}$ & $\begin{array}{l}\text { mature, fast rechargeable, high specific power / } \\
\text { high cost, low specific energy }\end{array}$ & $\begin{array}{l}\text { near-term } \\
\text { high }\end{array}$ \\
\hline $\mathrm{Ni}-\mathrm{Zn}$ & $\begin{array}{l}\text { high specific energy, high specific power, low cost / } \\
\text { short cycle life }\end{array}$ & $\begin{array}{l}\text { mid-term } \\
\text { high }\end{array}$ \\
\hline Ni-MH & $\begin{array}{l}\text { high specific energy, high specific power, fast rechargeable / } \\
\text { high cost }\end{array}$ & $\begin{array}{l}\text { near-term } \\
\text { very high }\end{array}$ \\
\hline $\mathrm{Zn} / \mathrm{Air}$ & $\begin{array}{l}\text { mechanically rechargeable, low cost, very high specific energy / } \\
\text { low specific power, cannot accept regenerative energy }\end{array}$ & $\begin{array}{l}\text { mid-term } \\
\text { very high }\end{array}$ \\
\hline Al/Air & $\begin{array}{l}\text { mechanically rechargeable, low cost, very high specific energy / } \\
\text { very low specific power, cannot accept regenerative energy }\end{array}$ & $\begin{array}{l}\text { near-term } \\
\text { low }\end{array}$ \\
\hline $\mathrm{Na} / \mathrm{S}$ & $\begin{array}{l}\text { high specific energy, high specific power / } \\
\text { high cost, safety concerns, need of thermal management }\end{array}$ & $\begin{array}{l}\text { mid-term } \\
\text { moderate }\end{array}$ \\
\hline $\mathrm{Na} / \mathrm{NiCl}_{2}$ & $\begin{array}{l}\text { high specific energy / } \\
\text { high cost, need of thermal management }\end{array}$ & $\begin{array}{l}\text { mid-term } \\
\text { high }\end{array}$ \\
\hline Li-Polymer & $\begin{array}{l}\text { very high specific energy, high specific power / } \\
\text { weak low-temperature performance }\end{array}$ & $\begin{array}{l}\text { mid-term } \\
\text { high }\end{array}$ \\
\hline Li-Ion & $\begin{array}{l}\text { very high specific energy, very high specific power / } \\
\text { high cost }\end{array}$ & $\begin{array}{l}\text { mid-term } \\
\text { very high }\end{array}$ \\
\hline
\end{tabular}

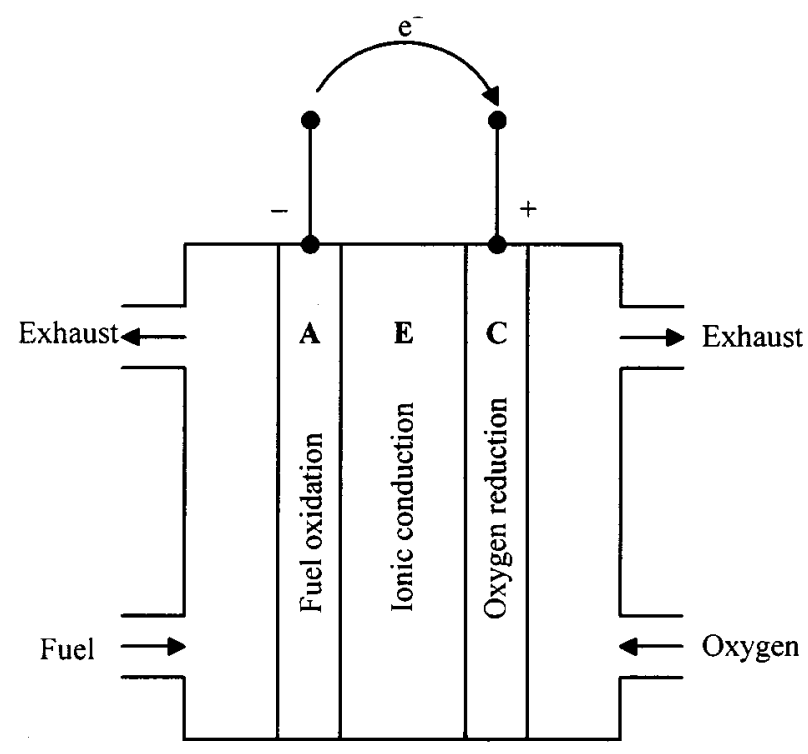

Fig. 25. Basic principle of FCs.

electrical energy. In contrast to a battery, the FC generates electrical energy rather than stores it and continues to do so as long as a fuel supply is maintained. Its advantageous features are efficient conversion of fuel to electrical energy, quiet operation, zero or very low emissions, waste-heat recoverable, rapid refuelling, fuel flexibility, durable, and reliable. As shown in Fig. 25, an FC basically consists of three major components, namely, the anode (A), cathode (C), and electrolyte (E). The anode (fuel electrode) provides a common interface for the fuel and electrolyte, catalyzes the fuel oxidation reaction, and drives electrons to the external circuit. On the other hand, the cathode (oxygen electrode) provides a common interface for the oxygen and electrolyte, catalyzes the oxygen reduction reaction, and receives electrons from the external circuit. Between the anode and cathode, the electrolyte functions to transport one
Table 9

Theoretical Energy Contents of Prominent Fuels

\begin{tabular}{lll}
\hline & $\begin{array}{l}\text { Specific energy } \\
(\mathrm{Wh} / \mathrm{kg})\end{array}$ & $\begin{array}{l}\text { Energy density } \\
\text { (Wh/l) }\end{array}$ \\
\hline Compressed hydrogen gas $^{\mathrm{a}}$ & 33600 & 600 \\
Liquid hydrogen $^{\mathrm{b}}$ & 33600 & 2400 \\
Magnesium hydride & 2400 & 2100 \\
Vanadium hydride & 700 & 4500 \\
Methanol & 5700 & 4500 \\
Petrol & 12400 & 9100 \\
\hline a At ambient temperature and $20 \mathrm{MPa}$ & \\
b At cryogenic temperature and $0.1 \mathrm{MPa}$ &
\end{tabular}

of the ionic species involved in the fuel and oxygen electrode reactions and also prevents the conduction of electrons.

Hydrogen seems to be an ideal nonpolluting fuel for the FC because it has the highest energy content per unit of weight of any fuel and the by-product is just plain water as a result of the $\mathrm{FC}$ reaction

$$
2 \mathrm{H}_{2}+\mathrm{O}_{2} \rightarrow 2 \mathrm{H}_{2} \mathrm{O}
$$

Since hydrogen is not a primary fuel, it is generally derived from various primary fuels such as hydrocarbons, methanol, and coal by means of a fuel processor. There are three major ways of storing hydrogen. First, it can be stored as a compressed gas, the so-called CHG. Similar to the compressed natural gas, the CHG can be stored at 20-34.5 MPa in fiberglass-reinforced aluminum containers. Second, it can be chilled below its boiling point $\left(-253{ }^{\circ} \mathrm{C}\right)$ to form liquid hydrogen, which is then stored in cryogenic containers. Third, it can be brought to react with some metals such as magnesium and vanadium to form metal hydrides. The reaction is reversible, depending on the temperature of dissolution (up to about $300{ }^{\circ} \mathrm{C}$ ). Table 9 shows the theoretical energy contents of some prominent fuels, including hydrogen stored in various forms, liquid methanol, and liquid petrol. The CHG storage offers the advantages of being a lightweight, low cost, and mature technology with fast refuelling capability, but suffers from 
Table 10

Typical Characteristics of FCs

\begin{tabular}{lllllll}
\hline & PAFC & AFC & MCFC & SOFC & SPFC & DMFC \\
\hline Working temp. $\left({ }^{\circ} \mathrm{C}\right)$ & $150-210$ & $60-100$ & $600-700$ & $900-1000$ & $50-100$ & $50-100$ \\
Power density $\left(\mathrm{W} / \mathrm{cm}^{2}\right)$ & $0.2-0.25$ & $0.2-0.3$ & $0.1-0.2$ & $0.24-0.3$ & $0.35-0.6$ & $0.04-0.23$ \\
Projected life $(\mathrm{kh})$ & 40 & 10 & 40 & 40 & 40 & 10 \\
Projected cost (US\$ $/ \mathrm{kW})$ & 1000 & 200 & 1000 & 1500 & 200 & 200 \\
\hline
\end{tabular}

PAFC - Phosphoric acid fuel cell

AFC - Alkaline fuel cell

MCFC - Molten carbonate fuel cell

SOFC - Solid oxide fuel cell

SPFC - Solid polymer fuel cell also known as proton exchange membrane fuel cell

DMFC - Direct methanol fuel cell

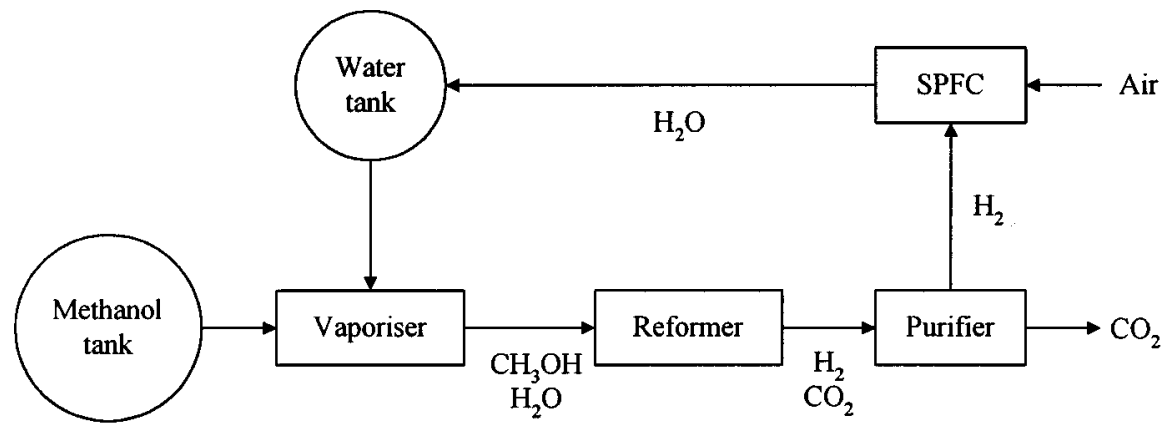

Fig. 26. Methanol-fuelled SPFC system.

bulky size and safety concerns. The liquid hydrogen offers both high specific energy and fast refuelling capability, but has the drawbacks of expensive production and distribution costs as well as high volatility. Although the metal hydrides can provide the merits of compact size and inherent safety, they suffer from either too high temperature of dissociation such as magnesium hydride $\left(287{ }^{\circ} \mathrm{C}\right)$ or relatively low specific energy such as vanadium hydride $(700 \mathrm{Wh} / \mathrm{kg})$.

Because of a vast number of variables among the FC systems, such as the type of fuel, type of electrolyte, type of fuelling, and operating temperatures, many classifications have appeared in the literature. Having done some of streamlining over the years, they are generally classified by the type of electrolyte, namely, acid, alkaline, molten carbonate, solid oxide, and solid polymer. Instead of using hydrogen as the fuel, carbon monoxide and methanol have also been adopted by some FCs. However, the by-product of these FCs becomes carbon dioxide, rather than plain water [43].

Detailed chemistries of the aforementioned FCs can be found in [43]. Typical characteristics of the aforementioned FCs are summarized in Table 10. Accordingly, both the molten-carbornate fuel cell (MCFC) and solid-oxide fuel cell (SOFC) suffer from very high-temperature operation, respectively, over $600^{\circ} \mathrm{C}$ and $900^{\circ} \mathrm{C}$, making them practically difficult to be applied to EVs. For the direct-methanol fuel cell (DMFC), the corresponding technology is still immature, although it has been developed for over 30 years. Also, its available power level and power density are too low for practical application to EVs. The others, namely, the phosphoric-acid fuel cell (PAFC), alkaline fuel cell (AFC), and solid-polymer fuel cell (SPFC), also known as the PEM FC, are all technically possible for EV applications-termed EV FCs.
With the advancement of SPFC (PEM) technology, the SPFC (PEM) takes advantages over the AFC for EV applications. The major reasons are due to its higher power density and longer projected life while maintaining the low working temperature and economical projected cost. Thus, recent research and development on FCs for EVs have been focused on the SPFC (PEM) technology. Ballard Power Systems and Daimler-Benz jointly produced a PEM FC bus in 1997, namely, the NEBUS. At present, the major challenge is how to significantly reduce the material cost of solid polymer membrane and platinum-electrocatalyzed electrodes. By retaining the definite advantage of liquid fuel while avoiding those shortcomings of the DMFC, the concept of methanol-fuelled PEM FC system is becoming more and more attractive for EVs. As shown in Fig. 26, methanol and water first are mixed, vaporized, and then converted into hydrogen and carbon dioxide gases via an onboard reformer. The resulting hydrogen gas is fed to the PEM FC to generate the desired electricity and the reusable pure water. The purifier functions to prevent any undesirable reformer by-products such as carbon monoxide gas from poisoning the precious electrocatalysts of the PEM FC. Although this technology seems to be contradictory to the pursuit of zero-emission vehicles, it is still environmentally friendly, as it does not generate harmful emissions such as carbon monoxide, nitrogen oxides, and hydrocarbons. Recently, Daimler-Benz and Ballard Power Systems have presented the first methanol-fuelled PEM FC-powered EV, namely, the NECAR 3, which can travel over $400 \mathrm{~km}$ using $38 \mathrm{~L}$ of liquid methanol. Toyota has also announced that its FC RAV4 EV has achieved the range of $500 \mathrm{~km}$ per tank of methanol. Even so, these methanol-fuelled PEM FCEVs are still in the development 


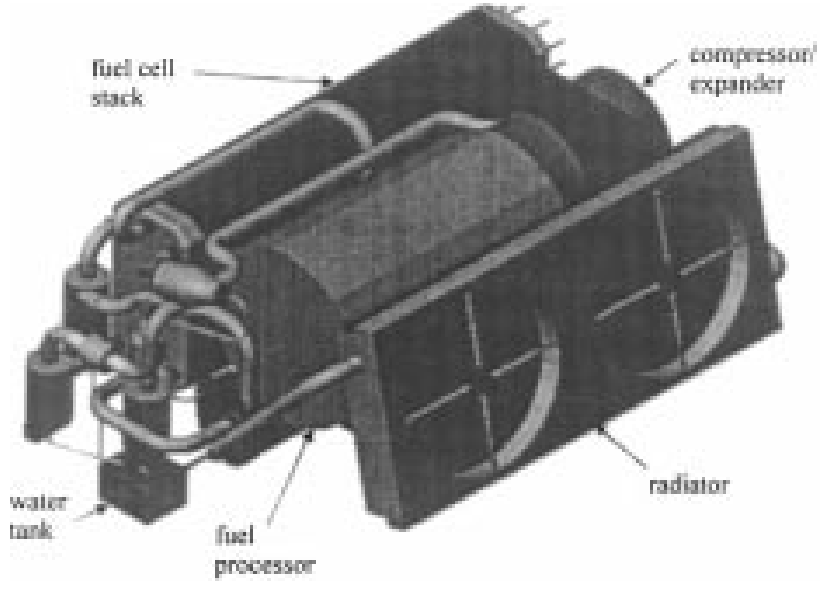

Fig. 27. $50 \mathrm{~kW}$ automative FC system (source: Energy Partners, L.C.).

stage. Fig. 27 shows a 50-kW automative FC system and Fig. 28 shows FCEV configuration.

Further extending the concept of liquid-fuelled FCEVs, research on extracting hydrogen from gasoline using an onboard reformer has been launched. The argument of this research is simple-hundreds of billion dollars have been invested in the way gasoline is distributed and it is impossible to change this infrastructure just because there are FCEVs that run in hydrogen or methanol. No matter this argument is agreeable or not, the success of this concept can definitely move the FCEVs approaching to reality. Recently, Chrysler has decided to realize this concept by demonstrating a gasoline-fuelled FCEV within the next few years. There is still much to be done in research and development of gasoline-fuelled FCEVs before they become commercially viable.

\section{Ultracapacitors}

Because of frequent start/stop operation of EVs, the discharge profile of the battery is highly variable. The average power required from the battery is relatively low while the peak power of relatively short duration required for acceleration or hill-climbing is much higher. The ratio of the peak power to the average power can be as high as 16:1 for a high-performance EV. In fact, the amount of energy involved in the acceleration and deceleration transients is roughly $2 / 3$ of the total amount of energy over the entire vehicle mission in the urban driving. Therefore, based on present battery technology, the design of batteries has to carry out the tradeoffs among the specific energy, specific power, and cycle life. The difficulty of simultaneously obtaining high values of specific energy, specific power, and cycle life has lead to some suggestions that EVs may best be powered by a pair of energy sources. The main energy source, usually a battery, is optimized for the range while the auxiliary source for acceleration and hill-climbing. This auxiliary source can be recharged from the main source during less demanding driving or regenerative braking. An auxiliary energy source that has received wide attention is the ultracapacitor [67].

In the foreseeable development of the ultracapacitor, it is not practical for it to be used as the sole energy source for
EVs because of its exceptionally low specific energy. Nevertheless, there are a number of advantages that can be resulted from using the ultracapacitor as an auxiliary energy source. The promising application is the so-called battery and ultracapacitor hybrid energy system for EVs. Hence, the specific energy and specific power requirements of the EV battery can be decoupled, thus affording an opportunity to design the battery that is optimized for the specific energy and cycle life with little attention being paid to the specific power. Due to the load levelling effect of the ultracapacitor, the high-current discharge from the battery is minimized so that the available energy, endurance, and life of the battery can be significantly increased. Moreover, compared to the battery, the ultracapacitor can provide much faster and more efficient energy recovery during regenerative braking of EVs, as well as operating at a very low temperature. Therefore, as a combined effect of load levelling and efficient energy recovery, the vehicle range can be greatly extended. Notice that system integration and optimization should be made to coordinate the battery, ultracapacitor, electric motor, and power converter. The power converter and corresponding controller should take care both the electric motor and ultracapacitor.

According to the goals set by the U.S. Department of Energy for the inclusion of ultracapacitors in EVs, the near-term specific energy and specific power should be better than 5 $\mathrm{Wh} / \mathrm{kg}$ and $500 \mathrm{~W} / \mathrm{kg}$, respectively, while the advanced performance values should be over $15 \mathrm{Wh} / \mathrm{kg}$ and $1600 \mathrm{~W} / \mathrm{kg}$. So far, it seems that none of the available ultracapacitors can fully satisfy these goals. Nevertheless, research and development of ultracapacitors for EV applications are actively engaged by some companies.

\section{EV INFRASTRUCTURE [52]-[56]}

\section{A. General Consideration}

To support the commercialization of EVs, an EV infrastructure is the underlying foundation, which includes the basic facilities and services to support the operation of a large number of EVs. In this section, only the infrastructure for battery EVs is discussed. The infrastructure for HEV will be much simpler because the size of battery is much smaller, it may also use the existing gasoline infrastructure. The infrastructure for FCEV will be quite different depending on the fuel used. In order to develop a successful battery EV infrastructure, we should pay attention on the following aspects:

1) availability of charging stations;

2) convenience of payment for charging;

3) standardization of EV batteries and charging;

4) regulation of clean and safe charging;

5) support from training and promotion;

6) impacts on power utilities.

\section{B. Charging Infrastructure}

The design of EV charging systems mainly depends on the level of charging currents to charge the EV batteries. There are three major current levels.

1) Normal Charging Current: The EV batteries can be charged by a rather low charging current, about $15 \mathrm{~A}$ 


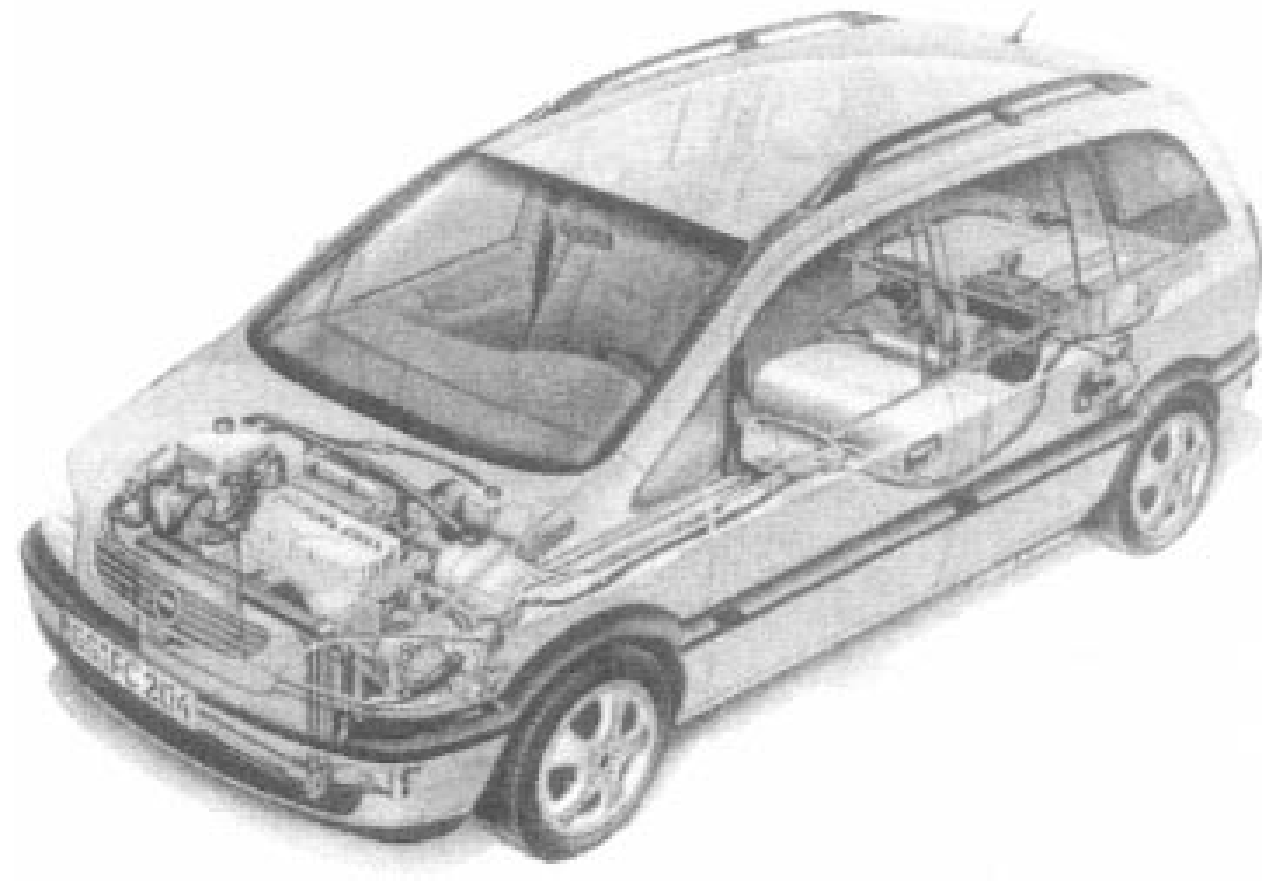

Fig. 28. FCEV configuration (source: OPEL Global Alternative Propulsion Centre).

and the charging period may last for over six hours. The operation and installation costs of the corresponding charger are relatively low since the power and current ratings involved are not of critical values. This charging current usually benefits to increase the charge efficiency and to extend the battery life.

2) Medium Charging Current: The EV batteries can be charged by a medium current of 30-60 A and the charging period may last for a few hours. The operation and installation costs of the corresponding charger are relatively higher than that for normal charging current because of the necessity to upgrade the charging equipment.

3) Fast Charging Current: The EV batteries can be charged up within a short time based on a high charging current of 150-400 A. In contrast to that using normal or medium charging current, the corresponding charger offers relatively low charge efficiency. Definitely, the corresponding operation and installation costs are high.

The normal charging current are adopted in both domestic and public charging infrastructures, whereas both the medium and fast charging currents are only found in the public charging infrastructure. Moreover, the fast charging current should only be adopted in those dedicated public charging stations because the corresponding current demand may cause detrimental effect on the power system network and maybe the impact of large current to the battery life.

\section{Impacts on Power System}

EVs bring both good and bad influences on power system. Positively, the batteries of EVs can be charged at offpeak pe- riods or at night so that the overall power demand can be levelled and the utilization of power system facilities can be improved. Negatively, the EV battery chargers are nonlinear devices which generate harmonic contamination to our power system, while the battery recharging of EVs at normal or peak periods creates additional current demand burdens on our power system.

1) Harmonic Compensation: In order to compensate the harmonic contamination on our power system, there are many possible measures proposed by researchers and engineers. Basically, these measures can be categorized into two groups device and system levels. In the device level, many new topologies of battery chargers are being proposed in such a way that the input harmonic current distortion is aimed to be minimal. These approaches rely on the invention of new battery chargers with minimum harmonic contamination and economically viable. In the system level, it can further be divided into two subgroups-passive and active filters. The passive filters can be simply phase-shifting transformers to suppress certain low-frequency harmonics or different combinations of inductor-capacitor sets to reduce those undesirable harmonics. On the other hand, the active filters are advanced power electronic systems that can online measure and diagnose the system harmonics so that they can instantaneously generate the same magnitude, but antiphase harmonics to neutralize the system harmonic content. As expected, these active filters need additional power source and sophisticated real-time control technology.

Recently, a new way for compensating harmonics generated by EV chargers has been proposed [53]. It is neither based on the invention of new EV chargers (device level) nor the adoption of new filters (system level). Rather than adding something to our power system, the basic idea is simply to 


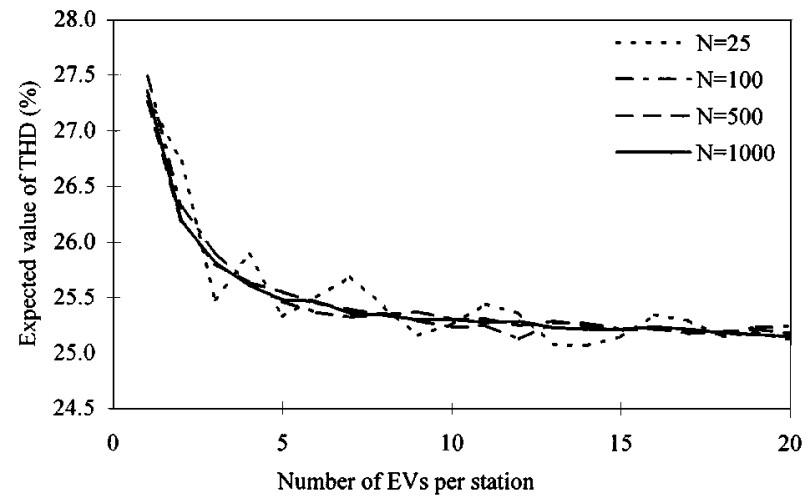

Fig. 29. Expected THD versus number of EVs at a charging station.

coordinate the number of EV chargers per charging station. Since the phase angles of those harmonic currents generated by one EV charger are normally different from those by another EV charger, there is a natural effect that harmonic compensation or even cancellation may occur. The more the number of chargers are being used per station, the higher the possibility to compensate the overall harmonic currents flowing to that charging station can be resulted. However, there is a practical limitation on the number of EV chargers per station because of the availability of space. Fig. 29 shows the expected total harmonic distortion (THD) versus number of EVs at a charging station, where $N$ is equivalent to the number of sampling in the Monte Carlo calculation.

2) Current Demand Minimization: In order to reduce the peak current demand due to the recharging of EVs, the concept of charging coordination has recently been proposed [54], [55]. The key of such concept is based on the coordination between charging current and charging time to charge a group of EVs at the same charging station. Hence, reducing the total maximum current demand, charging up the batteries as soon as possible, and achieving a flat load profile as far as possible. Basically, there are two types of coordination approaches: 1) distributive coordination and 2) centralized coordination.

In the case of distributive coordination, each EV needs to install a distributive coordination controller, which functions to maximize its individual charging current provided that the total current demand of the whole charging station is within the specified limit. Whenever there is any remaining current due to the chargeup or the leave of a particular EV, this unused current will be picked up by another EV based on the first-come first-serve (FCFS) arbitration. Since each EV simply knows the total current demand and aims to grasp the unused current to shorten its individual charging time, this approach takes the advantages of simplicity and low-cost implementation. However, the FCFS arbitration cannot redistribute the remaining current to other EVs in a balance way, thus the charging times of those EVs spread around. Also, since each EV charger knows only the total current demand of the charging station and nothing about the conditions of other EV chargers, some complicated control algorithms are not applicable to such approach.
In case of the centralized coordination, the charging station needs to install a central computer, which gathers the necessary information, such as the battery capacity, state of charge, current, and voltage ratings as well as expected charging times, from all EV chargers. Hence, intelligent arbitration made by the central computer is adopted so that the total current demand can be minimized while the EV charging times can be equalized as far as possible. This central coordination approach takes the advantages over the distributive counterpart that the current demand fluctuation can be reduced, the spread of charging times can be optimized, and those sophisticated control algorithms can be implemented. The drawback is the increase in implementation complexity and cost, which can be well outweighed by the associated advantages.

\section{EV COMMERCIALIZATION}

In response to the latest California rule that a mandate of $10 \%$ of vehicles put on the market must have zero emissions by 2003, it implies that Californian consumers may buy approximately $400000 \mathrm{EVs}$ in 2003. Recently, this mandate has been changed to accommodate Hybrid EV and FCEV with partial credit. Optimistically, if the other states adopt the same rule, the total EV sales in the USA will be very significant in 2003 (which is based on the estimation that the total vehicle sales in the USA will be of 18 million in 2003). In case other states may not enforce the same rule or may adopt a slower schedule, a conservative estimation of the total EV sales in the USA should be about 800000 in 2003. Taking into account some unforeseeable adverse factors, this amount may be reduced to 100 000. Apart from the USA, Europe and Asia also actively promote the EV markets. It has been forecasted that Europe and Asia each will create a market size of 50000 EVs. It should be noted that the California mandate will be reviewed periodically; therefore, the above estimation may be reviewed in due course. Also, the ULEVs, HEV, FCEV will have certain market share in the coming years. The Electric Vehicle Association of the Americas (EVAA) recently reported that 22 states throughout the USA have introduced legislation this year that would provide financial and/or nonfinancial incentives for electric drive technologies.

The key issues of successfully commercializing and promoting EVs lie in how to produce low-cost good performance EVs, leverage the initial investment, and provide an efficient infrastructure. The overall strategy should take into account how to fully utilize the competitive edge, share the market and resources, and produce EVs that can meet the market demand. Although specific strategies may vary with different manufacturers and countries and are very complex, the key element is the willingness and commitment of manufacturers and their industrial partners, governments and public authorities, electric utilities, and users. It is negative to say, "Let the market decide." Market forces are just abstract concept, derived from individuals who have different interests. Therefore, a wise initial strategy and agreement on market penetration are essential. Of course, 


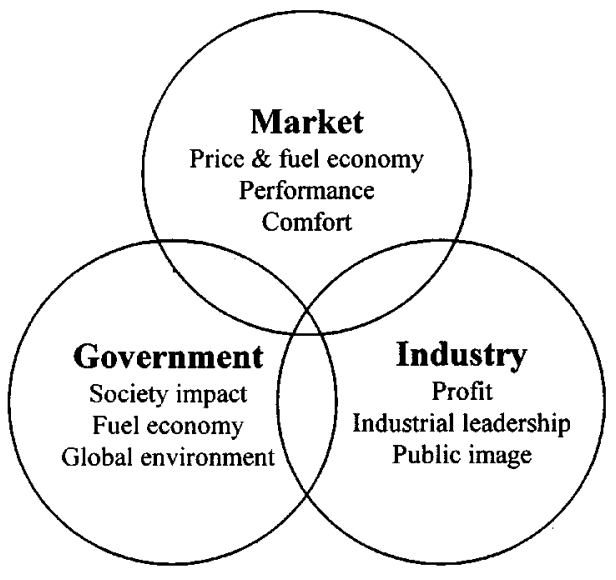

Fig. 30. Government, industry, and market.

the general expectation of the consumers must be fully considered.

The key of success is two integrations. First is the integration of society strength, which includes government's policy support, financing, and venture capital's interest, incentives for industry, and technical support from academic institutions. Second is the integration of technical strength, i.e., the effective integration of the state-of-the-art technologies of automobile, electrical, electronic, chemical, and material engineering.

At the beginning, EVs cannot compete with ICEVs in every application. Therefore, it is important to identify the niche markets that are feasible, e.g., small EV for community transportation, consequently to identify the required technical specifications and to adopt the system integration and optimization. In order to achieve cost effectiveness, a unique design approach and a unique manufacturing process should be developed. Excellent after-sales service and effective infrastructure are also essential. Fig. 30 shows the basic considerations of government, industry, and market. Although the viewpoint and emphases of these three parties are not identical, if these three parties are willing to cooperate and commit, a common interest and awareness can be achieved. This implies that the corresponding common area in Fig. 30 will be bigger and, hence, the chance of success will be greater.

Since EVs are not traditional vehicles, innovative marketing strategies and programs should be developed so that the financier, manufacturer, and customer can cooperate together at the win-win situation. As mentioned before, the major obstacles of marketing EVs are the short range and high initial cost. However, we should look into the overall economic analysis throughout the life cycle of EVs. The total cost of EVs including two parts: initial cost and operating cost. The initial cost of EVs is much higher than that of ICEVs due to the use of batteries as the energy storage device, while the energy storage device in ICEVs, namely, the fuel tank, represents only a minor fraction of the total vehicle cost. In order to relieve the burden of the EV customer, it is proposed to lease the battery, so that the initial cost of the EVs mainly only consists of the cost of the chassis, body, and propulsion system. Thus, the initial cost of EVs can be comparable or even cheaper than that of ICEVs if mass produced. Then, the operating cost of EVs will include three parts: maintenance cost, fuel cost, and battery rental cost. According to the statistic of EV operation in various countries, the maintenance cost of EVs accounts only 25\%-50\% of that of ICEVs. The ratio of fuel cost of EVs to ICEVs varies in different countries, since the oil price depends on the energy resource, energy policy, and tax system of different countries. In general, the oil price in the USA is much cheaper than in some Asian countries, such as China. Again, the electricity price depends on the primary energy used and price, efficiency of the power system, and the energy policy of different countries. Generally, the ratio of fuel cost of EVs to ICEVs is much cheaper in China as compared to that in the USA. The author has made an overall cost comparison of electric public minivans and diesel-engine public minivans in Hong Kong based on annual operation of $50000 \mathrm{~km}$ and using the battery-leasing program. Taking into account a reasonable profit of the battery-leasing company, the total annual operating cost of electric minivans is cheaper than that of diesel minivans. The saving of the operating cost is sufficient to compensate the higher initial cost of electric minivans within a duration of several years. This is because even without the battery, the initial cost of electric minivans may still be more expensive than that of diesel minivans, due to the absence of mass production.

The battery-leasing company may be a joint venture among the battery manufacturer, battery dealer, electric power utility, and oil company. This company owns the battery, leases the battery, provides charging, and other services to the customer and is responsible for the recycling of the battery. Since such a large quantity of batteries is managed by a leading company, it must be more cost effective. The aforementioned program will not only release the initial financial burden of the EV customer, but also relieve the psychological burden of the EV customer. Whenever the customer has a problem, he or she just needs to go to the service station. Depending on the customer's situation, the company may adopt fast, occasional, or normal charging or battery swapping (the battery will be recharged during the offpeak demand of the power system). Thus, it can leverage the energy demand and, hence, increase the overall energy efficiency.

The present EV market situation can be described as the following adverse circle of chain reaction: high initial price $\rightarrow$ low consumer satisfaction $\rightarrow$ low demand $\rightarrow$ lack interest of investment $\rightarrow$ no mass-production lines $\rightarrow$ no large-scale sales $\rightarrow$ high initial price. This situation should be changed by the following favorable circle of chain reaction: keen interest of investment $\rightarrow$ mass production lines $\rightarrow$ large-scale sales $\rightarrow$ low initial price $\rightarrow$ high consumer satisfaction $\rightarrow$ high demand $\rightarrow$ keen interest of investment.

We should strive for a clean, efficient, intelligent, and sustainable transportation means for the 21st century.

\section{CONCLUSION}

Environment protection and energy conservation have urged the development of EVs. However, the commer- 
cialization of EVs was not successful. The main reason was because they could not satisfy the consumers' need due to high cost and short range. Consequently, HEV and FCEV are recently rapidly emerging. Looking ahead in the next few decades, with the aid of new technologies, battery and advanced propulsion will continue to develop and BEV will be designed mainly for small vehicles in a niche market, such as community transportation. HEV can meet consumers' need and will grow in faster rate. The key issue of $\mathrm{HEV}$ is how to optimize the multiple energy source to obtain best performance at lower cost. FCEV will have long term potential to be the mainstream vehicle in the future because it is almost zero emission and comparible driving range to ICEV. However, because it is still in the early development state today, the major challenge of FCEV is how to develop low-cost FC, efficient fuel processor, and refuelling system. A proper engineering philosophy is essential for the guidance of strategic development of EVs

\section{ACKNOWLEDGMENT}

The author would like to thank the members of the research team especially, Dr. K. T. Chau, Dr. J. Quan, and Mr. Y. S. Wong, who provide substantial assistance in preparing the manuscript, and also to friends in the World Electric Vehicle Association, Electric Vehicle Association of Americas, European Electric Road Vehicle Association, and Electric Vehicle Association of Asia Pacific, including Japan Electric Vehicle Association, who provided updated information. The author would also like to thank the reviewers for constructive suggestions. Material presented in this paper is a collection of years of research and development by the author at the International Research Centre for Electric Vehicles, HKU, as well as the collaboration with international EV colleagues.

\section{REFERENCES}

[1] C. C. Chan and K. T. Chau, Modern Electric Vehicle Technology. London, U.K.: Oxford Univ., 2001.

[2] C. C. Chan, "An overview of electric vehicle technology," Proc. IEEE, vol. 81, pp. 1202-1213, Sept. 1993.

[3] - The 21stCentury Green Transportation Means-Electric Vehicles (in Chinese). Beijing, China: Tsing Hua Univ. Press, 2000, National Key Book Series.

[4] Proc. 7th Int. Electric Vehicle Symposium, Versailles, France, June 1984.

[5] Proc. 8th Int. Electric Vehicle Symposium, Washington, DC, Oct. 1986.

[6] Proc. 9th Int. Electric Vehicle Symposium, Toronto, ON, Canada, Nov. 1988.

[7] Proc. 10th Int. Electric Vehicle Symposium, Hong Kong, Dec. 1990.

[8] Proc. 11th Int. Electric Vehicle Symposium, Florence, Italy, Sept. 1992.

[9] Proc. 12th Int. Electric Vehicle Symposium, Anaheim, CA, Dec. 1994.

[10] Proc. 13th Int. Electric Vehicle Symposium, Osaka, Japan, Oct. 1996.

[11] Proc. 14th Int. Electric Vehicle Symposium, Orlando, FL, Dec. 1997.

[12] Proc. 15th Int. Electric Vehicle Symposium, Brussels, Belgium, Oct. 1998.

[13] Proc. 16th Int. Electric Vehicle Symposium, Beijing, China, Oct. 1999.

[14] Proc. 10th Int. Electric Vehicle Symposium, Montreal, QB, Canada, Oct. 2000.

[15] E. H. Wakefield, History of the Electric Automobile: Battery-Only Powered Cars. Warrendale, PA: Soc. Automotive Engineers, 1994.

[16] —-, History of the Electric Automobile: Hybrid Electric Vehicles. Warrendale, PA: Soc. Automotive Engineers, 1998.
[17] J. Fenton, Handbook of Vehicle Design Analysis. Warrendale, PA: Soc. Automotive Engineers, 1996.

[18] J. Beretta. (2000, Oct.) New tools for energy efficiency evaluation on hybrid system architecture. Proc. 17th Int. Electric Vehicle Symp. [CD-ROM].

[19] E. Inada. (2000, Oct.) Development of a high performance hybrid electric vehicle tino hybrid. Proc. 17th Int. Electric Vehicle Symp. [CD-ROM].

[20] A. Szumanowski, Fundamentals of Hybrid Electric Vehicle Drives. Warsaw, Poland: Warsaw-Radom Press, 2000.

[21] J. Van Mierlo. (2000, Oct.) Views on hybrid drivetrain power management. Proc. 17th Int. Electric Vehicle Symp. [CD-ROM].

[22] V. Wouk, "Hybrids: Then and now," IEEE Spectrum, vol. 32, pp. 16-21, July 1995.

[23] C. C. Chan and K. T. Chau, "An overview of power electronics in electric vehicles," IEEE Trans. Ind. Electron., vol. 44, pp. 3-13, Feb. 1997.

[24] C. C. Chan, K. T. Chau, J. Z. Jiang, W. Xia, M. Zhu, and R. Zhang, "Novel permanent magnet motor drives for electric vehicles," IEEE Trans. Ind. Electron., vol. 43, pp. 331-339, Apr. 1996.

[25] C. C. Chan, K. T. Chau, and J. M. Yao, "Soft-switching vector control for resonant snubber based inverters," in Proc. IEEE Int. Conf. Industrial Electronics, Nov. 1997, pp. 605-610.

[26] C. C. Chan, J. Z. Jiang, G. H. Chen, and K. T. Chau, "Computer simulation and analysis of a new polyphase multipole motor drive," IEEE Trans. Ind. Electron., vol. 40, pp. 570-576, Dec. 1993.

[27] C. C. Chan, J. Z. Jiang, G. H. Chen, X. Y. Wang, and K. T. Chau, "A novel polyphase multipole square-wave permanent magnet motor drive for electric vehicles," IEEE Trans. Ind. Applicat., vol. 30, pp. 1258-1266, Sept. 1994.

[28] C. C. Chan, J. Z. Jiang, W. Xia, and K. T. Chau, "Novel wide range speed control of permanent magnet brushless motor drives," IEEE Trans. Power Electron., vol. 10, pp. 539-546, Sept. 1995.

[29] C. C. Chan, Q. Jiang, Y. J. Zhan, and K. T. Chau, "A high-performance switched reluctance drive for P-star EV project," in Proc. 13th Int. Electric Vehicle Symp., vol. II, Oct. 1996, pp. 78-83.

[30] C. C. Chan, W. S. Leung, and C. W. Ng, "Adaptive decoupling control of induction-motor drives," IEEE Trans. Ind. Electron., vol. 37, pp. 41-47, Feb. 1990.

[31] C. C. Chan and H. Q. Wang, "New scheme of sliding-mode control for high performance induction motor drives," Proc. Inst. Electr. Eng. B, vol. 143, pp. 177-185, May 1996.

[32] T. J. E. Miller, Brushless Permanent-Magnet and Reluctance Motor Drives. New York: Oxford Univ. Press, 1989.

[33] - Switched Reluctance Motors and Their Control. Hillsboro, OH: Magna Physics, 1993.

[34] M. Mori, Y. Kido, T. Mizuno, T. Ashikaga, I. Matsuda, and T. Kobayashi, "Development of an inverter-fed six-phase pole change induction motor for electric vehicles," in Proc. 13th Int. Electric Vehicle Symp., vol. II, Oct. 1996, pp. 511-517.

[35] Y. Murai, J. Cheng, and M. A. Yoshida, "A soft-switched reluctance motor drives circuit with improved performances," in Proc. IEEE Power Electronics Specialists Conf., June 1997, pp. 881-886.

[36] M. A. Rahman and R. Qin, "A permanent magnet hysteresis hybrid synchronous motor for electric vehicles," IEEE Trans. Ind. Electron., vol. 44, pp. 46-53, Feb. 1997.

[37] Y. Sato, K. Fujita, T. Yanase, and S. Kinoshita. (1994, Dec.) New control methods for high performance PM motor drive systems. Proc. 14th Int. Electric Vehicle Symp. [CD-ROM].

[38] K. Yamada, K. Watanabe, T. Kodama, I. Matsuda, and T. Kobayashi, "An efficiency maximizing induction motor drive system for transmissionless electric vehicle," in Proc. 13th Int. Electric Vehicle Symp., vol. II, Oct. 1996, pp. 529-536.

[39] Y. J. Zhan, C. C. Chan, and K. T. Chau, "A novel sliding-mode observer for indirect position sensing of switched reluctance motor drives," IEEE Trans. Ind. Electron., vol. 46, pp. 390-397, Apr. 1999.

[40] G. Anerdi, A. Ancarani, R. Bianchi, M. Cipriani, D. Quaglia, G. Brusaglino, V. Ravello, and X. Andrieu, "Supercapacitor as a buffer to enhance energetical, operational and economical effectiveness of electric vehicle systems," in Proc. World Conf. Electric Vehicle Research, Development, and Operation, Nov. 1995, pp. 75-83.

[41] G. Anerdi, G. Brusaglino, A. Ancarani, R. Bianchi, G. Quaglia, U. Barberis, C. Ravera, P. H. Mellor, D. Howe, and P. Zegers, "Technology potential of flywheel storage and application impact on electric vehicles," in Proc. 12th Int. Electric Vehicle Symp., Dec. 1994, pp. 37-47. 
[42] D. Berndt , Maintenance-Free Batteries: Lead-Acid, Nickel/Cadmium, Nickel/Hydride: A Handbook of Battery Technology. New York: Wiley, 1997.

[43] L. J. M. J. Blomen and M. N. Mugerwa, Fuel Cell Systems. New York: Plenum, 1993.

[44] A. F. Burke, "Electrochemical capacitors for electric vehicles - technology update and inplementation considerations," in Proc. 12th Int. Electric Vehicle Symp., Dec. 1994, pp. 27-36.

[45] C. C. Chan, E. W. C. Lo, and W. X. Shen. (1999, Oct.) An overview of battery technology in electric vehicles. Proc. 16th Int. Electric Vehicle Symp. [CD-ROM].

[46] K. T. Chau, Y. S. Wong, and C. C. Chan, "An overview of energy sources for electric vehicles," Energy Convers. Manage., vol. 40, no. 10, pp. 1021-1039, July 1999.

[47] J. P. Cornu, V. Peski, E. D. Geeter, H. V. D. Broeck, A. Dufour, B. Marcenaro, P. Bout, and M. G. Woortman, "Hybrid fuel cell battery city bus technology demonstration project," in Proc. 12th Int. Electric Vehicle Symp., Dec. 1994, pp. 91-99.

[48] P. F. Howard, "Ballard zero emission fuel cell bus engine," in Proc. 12th Int. Electric Vehicle Symp., Dec. 1994, pp. 81-90.

[49] D. Linden, Handbook of Batteries, 2nd ed. New York: McGrawHill, 1995.

[50] I. F. Vermeulen, "Characterization of PEM fuel cells for electric drive trains," in Proc. 12th Int. Electric Vehicle Symp., Dec. 1994, pp. $439-448$

[51] Y. S. Wong, K. T. Chau, and C. C. Chan. (2000, Oct.) Optimization of energy hybridization in electric vehicles. Proc. 17th Int. Electric Vehicle Symp. [CD-ROM].

[52] C. C. Chan, K. T. Chau, and M. S. W. Chan. (1998, Oct.) Impact of electric vehicles to power system. Proc. 15th Int. Electric Vehicle Symp. [CD-ROM].

[53] M. S. W. Chan, K. T. Chau, and C. C. Chan, "Modeling of electric vehicle chargers," in Proc. IEEE Int. Conf. Industrial Electronics, Aug. 1998, pp. 433-438.

[54] - (1999, Oct.) Coordination of charging stations forelectric vehicles. Proc. 16th Int. Electric Vehicle Symp. [CD-ROM].

[55] K. T. Chau, M. S. W. Chan, and C. C. Chan. (2000, Oct.) Current demand minimization by centralized charging coordination. Proc. 17th Int. Electric Vehicle Symp. [CD-ROM].

[56] Recommended Practices and Requirements for Harmonic Control in Electrical Systems, IEEE Standard 519-1992, 1993.

[57] M. G. Kosowski. (1997, Dec.) Current status of electric vehicle codes and standards. Proc. 14th Int. Electric Vehicle Symp. [CD-ROM].

[58] P. Menga and A. Savoldelli, "Methodology for economical and managerial assessment of electric vehicles recharging infrastructures," in Proc. 13th Int. Electric Vehicle Symp., vol. I, Oct. 1996, pp. 748-755.

[59] U. Muntwyler, "Cost of an infrastructure for electric vehicles," in Proc. 13th Int. Electric Vehicle Symp., vol. I, Oct. 1996, pp. 383-389.

[60] J. J. Nowicki. (1997, Dec.) Building an electric vehicle infrastructure. Proc. 14th Int. Electric Vehicle Symp. [CD-ROM].
[61] J. M. Olsen and D. Edison, "National electric vehicle infrastructure working council health and safety committee update," in Proc. 13th Int. Electric Vehicle Symp., vol. II, Oct. 1996, pp. 164-170.

[62] K. Shimizu. (1997, Dec.) Status of Japanese EV standardization activities in '97. Proc. 14th Int. Electric Vehicle Symp. [CD-ROM].

[63] P. T. Staas, W. M. Grady, A. Aprapostathis, and R. S. Thallam, "A statistical method for predicting the net harmonic current generated by a concentration of electric vehicle battery chargers," IEEE Trans. Power Delivery, vol. 12, pp. 1258-1266, July 1997.

[64] C. B. Toepfer. (1997, Dec.) The EV as a vehicle for advancing electrical safety. Proc. 14th Int. Electric Vehicle Symp. [CD-ROM].

[65] "Assessment of Electric Vehicle Impacts on Energy, Environment and Transportation Systems," International Energy Agency, 1999.

[66] Fuel Cell Handbook, 5th ed., U.S. Dept. of Energy, Washington, DC, 2000.

[67] A. Burke, "Ultracapacitors: Why, how and where is the technology," J. Power Sources, vol. 91, no. 1, pp. 37-50, Nov. 2000.

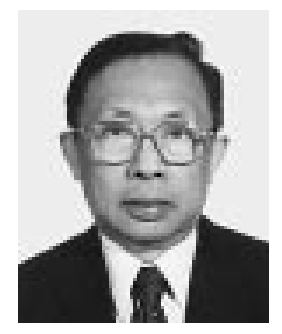

C. C. Chan (Fellow, IEEE) received the B.Sc. degree from the China University of Mining and Technology, Beijing, China, the M.Sc. degree from the Tsinghua University, Beijing, China, and the Ph.D. degree from the University of Hong Kong, Hong Kong, in 1957, 1959 and 1981, respectively, and was awarded the Honorary D.Sc. degree from the Technical University of Odessa, Odessa, Ukraine, in 1992.

$\mathrm{He}$ has 11 years of industrial experience and 29 years of academic experience. He is currently the Honda Chair Professor of Engineering and has served as the Head of the Department of Electrical and Electronic Engineering, the University of Hong Kong. He is the Founding President of the International Academy for Advanced Study, Shanghai, China, and the Honorary President of the University of Science and Technology, Tianjin, China. He has served as a Visiting Professor and an Honorary Professor of a number of well-known universities around the world, including the University of California, Berkeley, and MIT as well as a By-Fellow of Churchill College, Cambridge University. He also has served as the President of the Hong Kong Institution of Engineers and the President of the World Electric Vehicle Association. He has authored or coauthored seven books and over 200 technical papers and holds seven patents.

Prof. Chan is a Fellow of the Royal Academy of Engineering, U.K., the Chinese Academy of Engineering, the Ukraine Academy of Engineering Sciences, and the Hong Kong Academy of Engineering Sciences and is an Academician of the Chinese Academy of Engineering. He received the IEE International Lecture Medal in 2000 and delivered lectures on electric vehicles worldwide. He was also selected as one of Asia's Best Technology Pioneers by Asiaweek in 2001. 